\title{
GLOBALIZACIÓN, AMPLIACIÓN DE LA UE Y NUEVOS PANORAMAS MIGRATORIOS: DESAFIOS DE LA ECONOMIA INFORMAL Y CONTINGENCIAS PARA «EL TRABAJO DECENTE»
}

BRANKA LIKIC-BRBORIC*

RESUMEN: El artículo aborda los cambios en curso en materia de bienestar, mercado de trabajo y los regímenes de la migración en relación a la globalización, la ampliación de la ue hacia el Este y el predominio de una visión neoliberal. Pone en relieve la conexión entre estos cambios y los impactos de las políticas neoliberales en los países post-socialistas con el aumento del desempleo, de la industrialización, la economía informal y los nuevos patrones de migración. También se analizan las respuestas institucionales a distintos niveles de gobierno, principalmente en el mundial y el de la UE, a los fenómenos de la economía informal, las nuevas formas de la inmigración legal y clandestina y el empleo. En este contexto, el artículo traza el desarrollo de la dimensión social de la globalización y la articulación de un enfoque inclusivo y política de derechos humanos basado en la gestión de la migración y la economía informal con un enfoque en la Organización Internacional del Trabajo (OIT); de la reformulación la justicia social en términos de "trabajo decente» para todos los trabajadores, incluso los que trabajan en la economía informal. Se argumenta que la inclusión de parámetros de trabajo decente, la dimensión social de la globalización en el proyecto de ampliación de la UE y el régimen de cambio de migración de la ue depende, tanto de su traducción en los contextos políticos nacionales y de las limitaciones establecidas por la devoción de los Estados de la UE, dominante incondicional a la omC. También están las negociaciones y la competitividad global, que ponderan cuidadosamente la inclusión de las condiciones sociales sólo en la medida en que facilitan una disuasión del proteccionismo económico.

PALABRAS ClaVE: Patrones migratorios, política neoliberal, economía informal, bienestar, globalización.

ABSTRACT: The article addresses the on-going changes in welfare, labour market and migration regimes in conjunction to the globalization, EU enlargement eastwards and the dominance of a neoliberal vision. It highlights the connection between these changes and the impacts of neo-liberal policies in post-socialist countries with rising unemployment, de-industrialization, informal economy and new migration patterns. It also discusses institutional responses at different levels of governance, primarily on the global and Eu levels, to the phenomena of the informal economy, new forms of legal and clandestine immigration and employment. Against this setting, the article traces the development of the social dimension of globalization and the articulation of an inclusive, human rights-based policy approach to migration management and the informal economy with a focus on the International Labour Organization (ILO)'s reformulation of social justice in terms of "decent work» for all workers, even those working in the informal economy. It is argued that the inclusion of decent work parameters and a social dimension of globalization into the project of Eu enlargement and changing eu migration regime is contingent on both its translation into national policy contexts and the limitations given by EU dominant states' unconditioned devotion to WTO negotiations and global competitiveness, that cautiously ponder inclusion of social conditions only inasmuch they facilitate a deterrence of economic protectionism.

KEYwORDs: Migration patterns, neoliberal policies, informal economy, welfare, globalization.

\footnotetext{
* Profesora Investigadora de Linkoping University, branka.likic-brboric@isv.liu.se Nota: Traducción del inglés por Luis Rodolfo Morán Quiroz.
} 


\section{INTRODUCCIÓN}

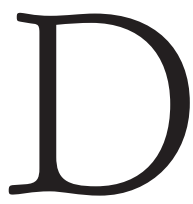

espués de la caída de la Unión Soviética y la transición de la economía socialista a una de mercado en el antiguo mundo comunista, hemos sido testigos de una acelerada tendencia globalizadora y la formación de un sistema de producción global, así como configuraciones regionales y nacionales de la economía política global. Las políticas de desregulación financiera, liberalización del comercio, reagrupamiento del Estado e integración del mercado regional, orientadas por la visión neoliberal de una economía global de laissez-faire, individualismo y el modelo empresarial angloamericano, han instigado la reestructuración industrial global y la internacionalización de la actividad económica. El cambio institucional y las revolucionarias innovaciones en el transporte y las tecnologías de la comunicación y la información, permitieron no sólo un cambio de la organización de la producción fordista a una posfordista, sino también un cambio de las estrategias corporativas nacionales a las transnacionales, que promueven la competitividad, eficiencia, productividad y reducción de costos.

El corolario más perturbador de la reestructuración económica global ha sido el aumento del desempleo estructural, asociado con crecientes inequidades sociales dentro de los países y entre ellos, así como la generación de nuevos patrones de exclusión ecónomica y social. No obstante, dada la tenaz persistencia del prefacio económico neoliberal, la réplica de los diseñadores de políticas ante estos predicamentos, todavía implica una mayor liberalización del mercado hacia una flexibilización excesiva de los mercados de fuerza de trabajo y la informalización del trabajo. Esta dinámica, aparentemente perpetua, también ha generado diversas estrategias informales de sobrevivencia individual y respuestas empresariales que, como último recurso, dependen de mano de obra aún más barata, precaria y, por lo general, indocumentada. En conjunción con la globalización, la ampliación de la Unión Europea (UE) hacia el este ha reforzado estas tendencias de la informalización y nuevas formas de migración transnacional, regular e irregular, hacia países y sectores más desarrollados que dependen de una fuerza de trabajo más adaptable.

El aumento en el desempleo, la migración y la economía informal ciertamente han incapacitado a las políticas económicas nacionales, desafiado los programas de bienestar establecidos, a los regímenes de trabajo y migración en las economías avanzadas y fomentado la búsqueda de soluciones posnacionales. Las más inquietantes respuestas a estos problemas han sido el aumento del populismo, el fundamentalismo, el terrorismo y las redes criminales transnacionales, relacionadas todas con el fenómeno de la migración, su percepción, experiencias y ubicaciones. Hemos visto de qué manera la migración se ha convertido en uno de los temas políticos centrales de la Ue, así como en Estados Unidos, tanto como un problema social de "multiculturalismo», es decir, de integración de los migrantes legales, como 
problemas económicos asociados con el empleo informal de los migrantes clandestinos que pone en peligro la premisa existente de empleo regular.

Este ensayo aborda las nuevas configuraciones de la migración y las prácticas del empleo informal que conlleva la globalización y la ampliación de la ue hacia el este, junto con la influencia de estos procesos en la todavía vigente transformación de los regímenes de bienestar y de migración europeos, así como de las instituciones del mercado de fuerza de trabajo. El principal objetivo es discutir las respuestas institucionales ante el fenómeno de la economía informal, las nuevas formas de inmigración, tanto legal como clandestina, y el empleo en los diferentes niveles de la gobernanza, primordialmente desde la perspectiva global y de la UE. El ensayo se divide en cuatro secciones. La primera rastrea, brevemente, las ideas, dinámicas y fuerzas detrás de los procesos de globalización en su versión de la ampliación de la UE en una perspectiva histórica, con una mirada a las configuraciones regionales de las economías políticas y la escalada de pobreza, desigualdad social y regional, la migración y la economía informal. Se concede una consideración especial a los procesos de transformaciones postsocialistas y a la europeización de los países del centro y el este de Europa, las consecuencias socioeconómicas concomitantes y las nuevas presiones de la migración. La segunda parte describe los efectos socioeconómicos de la globalización y las presiones de la migración en el contexto europeo y las respuestas nacionales y transnacionales de los Estados miembros de la UE ante estos desafíos, en especial en cuanto a la manera en que los temas de la competitividad global, la movilidad, los derechos de ciudadanía y de los trabajadores están siendo enmarcados dentro de la agenda de la UE. Aborda la reciente ampliación de la ue hacia el este, los nuevos patrones de migración europeos y su desafío al mercado nacional de trabajo, los regímenes de bienestar y migratorio en las economías avanzadas de la UE, incluidas las ideas del modelo social europeo y la justicia social global. La tercera sección rastrea el desarrollo de una dimensión social de la globalización y aborda la articulación de un enfoque de políticas con base en los derechos humanos, inclusiva, hacia el manejo de la migración y la economía informal, con un énfasis en la reformulación de la Organización Internacional del Trabajo (OIT) sobre la justicia social en términos de «trabajo decente» para todos los trabajadores, incluso aquellos que trabajan en la economía informal. La sección final, de conclusiones, discute las posibilidades y los obstáculos relacionados con la inclusión de los parámetros del trabajo decente y una dimensión social de la globalización en el proyecto de ampliación de la UE y un cambio del régimen de migración de la UE.

El análisis dirigido a captar estas complejas dinámicas y la discusión subsiguiente está relacionado con los debates actuales respecto a las limitaciones económicas de la globalización, el papel de las ideas y la capacidad de las «comunidades epistémicas» de configurar la agenda de políticas sociales en los ámbitos nacional y transnacional, en términos de una mayor justicia distributiva (Deacon, 2005). A este respecto, se ha utilizado una perspectiva institucional más amplia, 
que combina análisis históricos, organizacionales y discursivos institucionales, como marco de referencia, y se ha planteado el tema del papel de las ideas en la transformación de los arreglos institucionales (Campbell y Pedersen, 2001). Del mismo modo, las ideas alternativas, que enfatizan el papel preponderante de la política social en la globalización y las contingencias para su puesta en práctica, se discuten dentro de la trayectoria económica global y los cambiantes marcos institucionales, tanto en los niveles de la Ue como en los nacionales.

\section{La globalización, la economía informal y los nuevos escenarios migratorios}

Las últimas tres décadas han sido testigos de un poderoso avance de la liberalización económica global encabezado por los Estados y las empresas. El diseño de una arquitectura institucional transnacional y el rediseño de los marcos institucionales nacionales, encaminados a permitir el libre movimiento de capital y el libre comercio, han sido anunciados por el cambio ideológico previo hacia el neoliberalismo que sucedió a la crisis económica de los años setenta en las economías avanzadas. Es posible rastrear una extensión global dispar, aunque progresiva, del neoliberalismo y una concomitante reestructuración de un sistema capitalista global de producción en tres procesos reforzantes:

- El «cambio hacia la derecha» de los años ochenta en Estados Unidos y Gran Bretaña (reaganomics y thatcherismo), su difusión a los otros países de la Organización para la Cooperación y el Desarrollo Económico (OCDE) y la imposición de un régimen de ayuda neoliberal, el llamado Consenso de Washington, en los países subdesarrollados endeudados, en especial en América Latina;

- la compleja configuración, en los años noventa, de la Europa posterior a la guerra fría, tras la debacle, en 1989, del socialismo y las transiciones poscomunistas y su interjuego con los procesos de europeización;

- el cambio de milenio, que trajo consigo el rejuvenecimiento del sector conservador en Estados Unidos y el compromiso de la Ue ampliada con la institucionalización del régimen económico global, así como un proceso correlativo de transformación socioeconómica en las economías avanzadas.

Estos procesos interrelacionados y reforzantes -que reflejan el «mapeo» neoliberal de los nuevos «panoramas del capital» global (Goldman et al., 1998/2003)han afectado tanto a las economías en desarrollo como a las avanzadas en el mundo entero, aunque en diferentes formas y en diferentes momentos. Sin embargo, independientemente de las distintas consecuencias regionales, la configuración de la economía política global se ha visto marcada por dos fenómenos en común: una creciente informalización de la economía y un incremento en la migración. Ambos son vistos como efectos de las crecientes desigualdades económicas y de la creciente polarización socioeconómica. Igualmente, configuran las 
luchas ideológicas y políticas más amplias en cuanto a la remodelación de los «sistemas sociales de producción» $»^{1}$ globales, regionales y nacionales.

\section{EL SURGIMIENTO DEL NEOLIBERALISMO Y EL «CAMBIO A LA DERECHA» EN EL ESCENARIO INTERNACIONAL DE LOS AÑOS OCHENTA}

El principal impulso de la actual globalización económica fue, y continúa siendo, la respuesta de las políticas neoliberales ante la crisis económica de los años setenta en las economías avanzadas y el impacto del «cambio hacia la derecha» en la reforma del régimen de Bretton Woods y la política de desarrollo. Como es sabido, el neoliberalismo está relacionado con un conjunto de ideas que incluyen el monetarismo de Milton Friedman, el liberalismo económico conservador de Friedrich Hayek y de diferentes escuelas de economía política que alaban el interés propio y las fuerzas del mercado y que comparten el desagrado por la intervención del Estado (Waligorski, 1990). Las medidas relacionadas de las políticas económicas en el lado de la oferta, que se centran en los impuestos y en los cortes de gasto en el bienestar, fueron justificadas y configuradas de acuerdo con una explicación de la crisis económica en términos de la «reducción de ganancias» causada por altos costos salariales y por los altos precios de las materias primas. Las respuestas políticas implicaron una doble aproximación dirigida a recortar los costos de producción, tanto los nacionales como los internacionales.

En lo que respecta a las decisiones de política doméstica, a lo largo de los años ochenta los diseñadores de política económica estadounidenses y británicos denunciaron al keynesianismo y adoptaron al monetarismo, la estabilización macroeconómica, la desregulación, la austeridad en el gasto estatal, la privatización y la confrontación con los sindicatos, al tiempo que promovieron la creación de mercados laborales flexibles y las políticas de «reducción de salarios» (wage squeeze) (Gordon, 1996; Peterson, 1994). Según Henk Overbeek (2003b: 1-2), «el monetarismo restauró al desempleo su papel previo como mecanismo regulador en el manejo de la economía», mientras que generó al mismo tiempo un creciente desempleo y una presión a la baja en los salarios. Como consecuencia, la reestructuración industrial que siguió no sólo implicó el cambio de sistemas de producción fordistas a posfordistas, sino también una rápida desindustrialización, una enorme caída en el empleo industrial y una deconstrucción del Estado de bienestar (Overbeek, 2003a: 26). Con base en el «experimento británico», Guy Standing (1989: 286-291) muestra que la puesta en práctica del paquete de políticas neoliberales derivó en un incremento de la desigualdad, un elevado desempleo que llegó a más de tres millones en 1987, junto con un aumento en la flexibilización, la estratificación y la

${ }^{1}$ El sistema social de producción se entiende como el sistema empresarial y la organización industrial relacionada, en su interjuego con una configuración social más amplia de los marcos institucionales, incluyendo las normas y valores sociales (Hollingsworth 2002: 240). 
informalización de la fuerza laboral. De igual manera, Saskia Sassen (1989) identifica los nuevos patrones socioeconómicos y geográficos de la reestructuración postindustrial de los años ochenta en Estados Unidos. Esboza las tendencias, causas y efectos socioeconómicos de la polarización económica y de la creciente informalización de las actividades económicas en general y en el sector de servicios en particular, en donde los disparados salarios de los especialistas financieros y en tecnología generaron mayor demanda de servicios domésticos.

Queda claro que en el contexto de un incremento en la competencia internacional por parte de los países con bajos salarios, la informalización ha resultado estar configurada estructuralmente por diferencias cada vez mayores en las posibilidades de obtener ganancias y en la desigualdades de ingresos dentro y entre los diversos sectores, así como por la generación de demanda de bienes y servicios de bajo costo, tanto en el sector formal como dentro de las comunidades más pobres, principalmente de inmigrantes en las metrópolis estadounidenses (Sassen, 1998; Stepick, 1989). Un gran número de pequeñas empresas y de firmas en apuros de tamaño mediano en los sectores de construcción, textiles, mobiliario, electrónica, calzado, hotelería, restaurants y servicios domésticos sobrevivieron e incluso han crecido al apoyarse en la producción y distribución informal de bienes y servicios. Esto, sin embargo, conllevó una segmentación de género y étnica en el mercado laboral y el deterioro de las condiciones de trabajo y las relaciones de empleo.

Estos estudios y los relacionados con el tema de la generación de la economía informal en varios países en diferentes etapas de desarrollo trajeron consigo una innovadora perspectiva estructuralista a la conceptualización de la economía informal (Castells y Portes, 1989), que cuestionó tanto la concepción dualista convencional como la legalista auspiciosa del «sector informal» (Cf. Chen et al., 2004). La primera conepción, es decir, la concepción dualista rígida, desarrollada por los expertos de la ort en los años setenta, asigna la incidencia de un sector informal insignificante y apartado a las economías tradicionales menos desarrolladas y a las estrategias de supervivencia de la fuerza de trabajo de escasa calificación en los contextos urbanos -que se espera se diluya con la modernización económica. El segundo enfoque, legalista, planteado por Hernando de Soto (1989), atribuía el crecimiento de la economía informal a las respuestas racionales ante los altos costos de la regularización y a las actividades empresariales innovadoras, una explicación que los neoliberales han utilizado entusiastamente como apoyo de las políticas de desregulación en general y de la promoción de los derechos de propiedad privada en los países en desarrollo.

Desde la perspectiva estructuralista, la insurgencia en contra de la excesiva regulación del Estado, el Estado de bienestar y el poder organizativo de la fuerza de trabajo en las economías avanzadas son tan sólo una de las causas de la economía informal, concebida como «la producción no regulada de bienes que de otra forma serían bienes y servicios lícitos» (Castells y Portes, 1989: 15). La creciente economía informal también es vista como inmanente al desarrollo capitalista 
global y estrechamente entrelazada con la reconfiguración de la economía formal en el contexto de una competencia en aumento. De ahí que la informalización se identifique como una estrategia de Estado de los países en desarrollo y de los nuevos países industriales, de manera notable China e India, para competir por la inversión extranjera directa (IED) y los mercados extranjeros. Finalmente, el empleo informal, asociado frecuentemente con la migración irregular, resultó ser la única estrategia de supervivencia para los trabajadores que han perdido sus empleos en muchos países en desarrollo agobiados por la crisis de deuda y el "giro a la derecha» de alcances internacionales.

Este "giro a la derecha» internacional, se dio en unión con la crisis de la deuda en los países en desarrollo, principalmente en América Latina, pero también en países de África y algunos países socialistas, como Yugoslavia y Polonia. Tras la «revolución silenciosa» en el paradigma de desarrollo y el discurso a lo largo de los años ochenta, el modelo convencional de desarrollo se ha visto configurado por el régimen multilateral de ayuda dominado por Estados Unidos y las instituciones financieras internacionales (IFIS), específicamente el Banco Mundial (BM) y el Fondo Monetario Internacional (FMI) (Boughton, 2001). Haciendo referencia a la ubicación misma de las IFIs y la influencia de Estados Unidos en la formulación del cartabón de políticas para el modelo de reestructuración de la deuda, el modelo fue bautizado como "Consenso de Washington» (Lavigne, 1999: 159; Williamson, 2000). Reflejaba ello el giro hacia una nueva "síntesis clásica» (Boughton, 2001: 54) que abogaba por la liberalización comercial y financiera y la promoción de una economía de mercado. En 1989, John Williamson identificó diez reformas de política que se practicaron activamente en América Latina durante los años ochenta y, que él creía que una administración estadounidense conservadora apoyaría, que se traducían en la condicionalidad de los programas de ajuste estructural. ${ }^{2}$ Los endeudados países en desarrollo se vieron así obligados a abrir sus mercados a los bienes industriales y de consumo provenientes de los países de la OCDE, al tiempo que exportaban materias primas bajo términos comerciales muy poco favorables. Mientras que esto tuvo como consecuencia menores costos internacionales de producción para las multinacionales en las economías avanzadas, las economías en desarrollo experimentaron un «doble estrujamiento» entre los altos costos del servicio de la deuda y los precios en picada de las materias primas, en especial los metales y el petróleo, en las principales casas de bolsa.

A pesar de los desacuerdos en lo que respecta al impacto socioeconómico en general de la actual oleada de globalización, la evidencia confirma que la puesta en práctica de los paquetes de políticas neoliberales, tanto en los países en desarro-

\footnotetext{
2 Estas políticas incluían: disciplina fiscal, retiro del Estado, amplias reformas impositivas y liberalización financiera y del comercio, una robusta orientación a la exportación y tasas de cambio unificadas y competitivas, promoción de la inversión extranjera directa, privatización de las empresas propiedad del Estado, desregulación y protección de los derechos de propiedad y su promoción en el sector informal (Lavigne, 1999: 160; Williamson, 1990).
} 
llo como en los antiguos países socialistas en Europa central y del este han derivado en un aumento de la desigualdad, pobreza, desempleo, desindustrialización, expansión de la economía informal e ilegal, captura del Estado, conflictos violentos, colapso del Estado y nuevas emergencias (Chen et al., 2004; Milanovic, 2003; Putzel, 2005; Wade, 2005). ${ }^{3}$ Además, la restructuración económica radical, las reformas comerciales y financieras que se moldearon para atraer y garantizar la IED, al tiempo que estipulaban un retiro del Estado, han creado a la vez factores de empuje y vías para los nuevos flujos migratorios hacia los países industriales avanzados (Sassen, 1988).

La formación, en los años ochenta, orientada a la inclusión de las diferentes economías en el orden económico mundial y sus resultados principalmente excluyentes en términos de un marco en decadencia de la ciudadanía social, también ha configurado las nuevas dinámicas, panoramas y políticas de migración transnacional y nacional. Tomando en cuenta la tensión generada por la reestructuración industrial, no es de sorprender que América Latina y Asia fueran las principales regiones de salida hacia Estados Unidos, con un aumento en la migración irregular, en especial aquella proveniente de México. La Europa de los años ochenta, por otro lado, habría de configurarse por el fin del sistema de trabajadores huéspedes debido al aumento en el desempleo, los regímenes migratorios más restrictivos y el proyecto de la ampliación europea hacia Grecia, España y Portugal. Estos son importantes factores que están configurados por los nuevos panoramas y rasgos de la migración europea. Los países del sur de Europa, que anteriormente enviaban trabajadores huéspedes al oeste de Europa, se han convertido ahora en la nueva puerta de entrada hacia Europa de un número creciente de migrantes irregulares provenientes de África, el Medio Oriente y Asia, que llegan a cubrir la demanda de empleos de escaso pago, casuales e informales en la agricultura, los textiles, la construcción y los servicios domésticos (King y Rybaczuk, 1993). Bimal Ghosh (1998: 10-13) reportó estimaciones que van de los 400,000 a los 800,000 migrantes irregulares tan sólo en Italia, mientras que España, Portugal, Alemania, Francia, Suiza, Holanda, Bélgica y Reino Unido presentaron un número creciente de migrantes indocumentados a lo largo de la década de los noventa. Él define la migración irregular como "genéricamente todos los traslados entre países que se dan fuera de las normas regulatorias de los países de origen, tránsito y recepción» (Ghosh, 1998: 9). La explosión de la migración irregular se explica aquí por la contradicción entre la creciente demanda de mano de obra barata y la imposición de controles fronterizos cada vez más estrictos en los países en desarrollo y en sus marcos transnacionales, como la UE, por un lado, y las presiones hacia la emigración en los países de origen, por el otro. De ahí que tanto la «migración para la supervi-

\footnotetext{
${ }^{3}$ Jeffrey Sachs (2005), uno de los ingenieros detrás del paquete de políticas, que trabaja ahora en temas de paliación de la pobreza, admite el fracaso, pero lo atribuye básicamente a la falta de comprensión de las contingencias geográficas y políticas específicas de cada país, así como a un apoyo financiero inadecuado por parte de las economías desarrolladas, no a las políticas per se.
} 
vencia», que toma forma a raíz de la extrema pobreza y de privación, y la «migración por oportunidad», estructurada por la falta de oportunidades y expectativas de mejores oportunidades de vida, estén relacionadas con las atribuladas economías de los países de origen, pero también con la inestabilidad política y las emergencias ambientales. Al mismo tiempo, sostiene Ghosh (1998: 69), la migración irregular ha asumido su propia dinámica interna y se ha visto afectada por las redes criminales e ilícitas de carácter transnacional, que controlan el tráfico de personas y sus nexos con prácticas ilegales como el trabajo infantil, la industria del sexo y la producción en talleres de alta explotación de mano de obra (sweatshops) que engloban e involucran, en muchas formas flexibles, a la economía formal tanto en el mundo desarrollado como en el mundo en desarrollo (Cf. Nordstrom, 2003). En conjunción con el proyecto neoliberal de desestructurar los regímenes de bienestar, los migrantes irregulares vinieron a dar nueva energía al proceso de dualización e informalización en las economías avanzadas, así como a la flexibilización de sus mercados de fuerza de trabajo en términos de segmentación étnica, racial y de género. No obstante, a pesar de las crecientes expresiones de descontento con el neoliberalismo, las revoluciones de 1989, la ruptura de la Unión Soviética y el inicio de las transiciones de la economía socialista a la economía de mercado, tan sólo han reforzado el proceso de globalización económica y han generado nuevos panoramas migratorios y geopolíticos en Europa.

\section{LAS TRANSFORMACIONES POSCOMUNISTAS, LA ECONOMÍA INFORMAL Y LA MIGRACIÓN DEL ESTE AL OESTE}

A lo largo de los años noventa, el Consenso de Washington también ha sido utilizado como cartabón para guiar los procesos de la transición postsocialista hacia la economía de mercado en todo lo ancho del segundo mundo, al tiempo que continúa subyaciendo al acelerado proceso de globalización (Likic-Brboric, 2003). La ampliación de la ue hacia el este y el acceso a ésta de ocho países de la Europa Central y del Este (CEE, por sus siglas en inglés) y antiguas economías comunistas se presentan como una transformación institucional poscomunista exitosa por parte de la UE y como un proyecto de paz. No obstante, la avasalladora reestructuración económica que se dio durante la llamada transición a una economía de mercado ha inflingido una recesión económica, un desempleo creciente, unos costos sociales significativos y una colosal caída en los estándares de vida, nuevas formas de exclusión social y de pobreza. Difícilmente resulta sorprendente que nuevos tipos de economía informal comenzaran a florecer en el contexto de una conspicua «desindustrialización», «desagriculturalización» y una debilitada economía formal en relación con la «crisis de transformación postsocialista». La «economía paralela», es decir, las diversas prácticas informales que permearon la economía de Estado como el empleo suplementario, el ausentismo, el desfalco y el uso no 
autorizado de los recursos del Estado, el favoritismo, la corrupción y la infracción de las reglas, han evolucionado en un «mejoramiento de la economía informal», mientras que un número creciente de negocios informales y la creciente importancia de la economía de sobrevivencia resultaron ser respuestas típicas relacionadas con la transformación postsocialista. (Neef, 2002: 14). Sin embargo, la forma más notable de economía informal en el contexto de la transformación está relacionado con la «descapitalización del Estado» como método exclusivo de la «acumulación privada de capital», configurando tanto al nuevo sistema político en términos de captura del Estado como a la transformación económica en términos de privatización ilegal y de economía sumergida. Estas prácticas generan también polarización económica y aun más informalización: las empresas privadas crecen «a expensas del Estado, el Estado transfiere las pérdidas a la población y la población en general hace lo mejor posible por minimizarlas» (Chavdarova, 2002: 67-68).

Aun cuando la creciente informalización por lo común se asocia con la contracción de la economía formal, Claire Wallace y Christian Haerpfer (2002: 35-36) enfatizan que diferentes vías de transición en diferentes países han derivado en diferencias en la significancia de la economía informal, según se miden en el relativo recurso de los hogares a la producción en el hogar. En 1998, más del 80\% de los hogares en Eslovenia, la República Checa y Hungría se basaban en la economía formal, en Eslovaquia y Polonia el 70\%. Una notable dependencia de la producción informal en el hogar, se registró en el círculo exterior de los países en los que había una dependencia marcadamente menor de la economía formal: Bulgaria, 27\%; Bielorusia, 26\%; Croacia, 18\%; Ucrania, 33\% y Rumania, 47\%. Mientras que las promesas y las políticas de acceso a la ue han puesto a Croacia, Rumania y Bulgaria en el camino expedito hacia «el gobierno de la ley», hasta el momento los resultados están lejos de ser satisfactorios.

Existe un acuerdo general en el sentido de que una economía formal que funcione está relacionada con la exitosa institucionalización de la economía de mercado. Sin embargo, en el reporte de la orT sobre economía informal en la región de CEE y la Mancomunidad de Estados Independientes (CIS, por sus siglas en inglés), Bettina Musiolek (2002) pone en tela de juicio las explicaciones convencionales de la exclusión social y la informalidad en términos del fracaso de la puesta en práctica de las reformas de mercado. De igual manera, cuestiona el impacto de la falta de instituciones y culturas de mercado en la región, las viejas burocracias comunistas, la captura del Estado, una insuficiente liberalización, altas cargas fiscales y la inestabilidad macroecónomica como las principales causas de la informalización. Por el contrario, encuentra que la política de privatizaciones y la falta de capital, en combinación, generaron flujos financieros ilegales y el financiamiento mal orientado de las pequeñas microempresas y el autoempleo y por ende generaron una desmercantilización y efectivización de las actividades económicas (Musiolek, 2002: 5). Además, tanto la privatización de las compañías estatales como el deterioro de los 
servicios públicos han tenido efectos. Las mujeres comenzaron a perder sus empleos y su posición social relativamente equitativa de la que gozaban durante el socialismo, sin posibilidades de reclamar empleos bien pagados. En cambio, se les ha reubicado en trabajo doméstico informal en sectores de baja paga y de escasa protección, como la industria del vestido, en donde las condiciones de trabajo no cumplen con los parámetros mínimos y no se reconocen los derechos de las trabajadoras.

El más inquietante hallazgo en el reporte de Musiolek es la deprimente influencia general del régimen comercial de la UE y el acceso injusto a las negociaciones con los países candidatos potenciales de la CEE, que incluían una persistente flexibilización y desregulación del mercado laboral con la intención de atraer la IED (Musiolek, 2002: 10). Segúnn Musiolek, «la desindustrialización de las economías de CEE/CIS ha estado acompañada por una reespecialización en la exportación de la producción que requiere mano de obra intensiva», en especial en el procesamiento de alimentos, manufactura de ropa y minería. En la industria del vestir, el régimen comercial de la ue promovió esquemas especiales, denominados proceso de ensamblaje en el exterior (outward processing trade schemes-OPT) o Lohnsystem al retirar las tarifas en estos bienes producidos por el esquema de OPT, al tiempo que utilizaba tarifas en «bienes sensibles» como acero, textiles y otras importaciones directas. ${ }^{4}$ El esquema OPT implica la subcontratación de empleos de mano de obra intensiva por medio de la importación de bienes semielaborados para su finalización y reexportación al país de origen. Los países de CEE/CIS se han convertido en el principal campo del esquema OPT en productos como calzado, ropa y ropa deportiva, mientras que los flujos de IED a estos países han permanecido modestos. De tal forma, Polonia y Rumania se han convertido en exportadores de ropa a la UE, mientras que la antigua Yugoeslavia y Bulgaria han seguido sus pasos. Los exportadores de ropa, que previamente eran exitosos en la antigua Yugoeslavia, han sido reducidos únicamente a los esquemas OPT. Esa concepción de las «ventajas competitivas» promueve, ciertamente, los arreglos informales de trabajo y apoya la afirmación de que los esquemas «OPT pueden ser denominados la entrada para la informalidad» (Musiolek, 2002: 16-17). Es claro que el proceso de acceso a la UE ha implicado tanto la desregularización como la re-regularización por medio de la emulación de un nuevo régimen comercial de la UE con el objetivo de evitar las antiguas regulaciones, las cuales se asegurba que eran rígidas. Las nuevas regulaciones flexibles «están creando relaciones laborales precarias en sus países de destino e incrementan la presión hacia la desrregulación de las relaciones laborales dentro de la UE, a menos que se les preserve por medio de fuertes medidas proteccionistas» (Musiolek, 2002: 18).

\footnotetext{
${ }^{4}$ Este aspecto también lo ilustran los ejemplos de la proliferación de empresas textiles sin ser igualada por los inspectores de trabajo adicionales; la presión internacional sobre Polonia para denunciar el salario mínimo legal a fin de atraer las inversiones, las presiones para liberalizar los mercados de trabajo por los "grandes inversionistas», la admisión informal de que la aplicación de las Convenciones de la ort en Bulgaria haría la subcontratación no competitiva.
} 
La crisis de la transformación, el desempleo y la prolongada pobreza en la región también han generado las condiciones estructurales que provocaron la migración este-oeste (Ardittis, 1994), que refleja tanto los rasgos generales de las migraciones globales como las particularidades regionales (Iglicka, 2002). En el reciente estudio de la UNESCO sobre migración laboral en Europa del este y Asia central, Katja Patzwaldt (2004: 4) ilustra cómo los trabajadores migran entre los países de la región «cayendo en cascada desde países más pobres hacia países más ricos». De tal forma, la gente de los países menos desarrollados en la región, como las repúblicas del Cáucaso y los estados de Asia central en el sur, se ve atraída hacia la república de Kazajstán o hacia Rusia. Aun cuando los migrantes laborales provenientes del este de Ucrania y Moldavia seleccionan a Rusia como su destino, los migrantes provenientes de Rusia, el oeste de Ucrania y Moldavia se trasladan a Europa central para continuar desde ahí, junto con los trabajadores provenientes de los nuevos países miembros y de acceso a la UE, hacia las economías avanzadas de la UE.

Krystina Iglicka (2002: 205) señala una nueva «movilidad primitiva» que se generó en el contexto del libre tránsito regional y del desempleo estructural persistente. Fue motivada económicamente por la diferencia entre la oferta y la demanda de mercancías, así como por los diferenciales de precios y de intercambio de divisas entre los países de la CEE y CIS. De hecho, los flujos regionales irregulares y circulares ya funcionaban durante la década de los ochenta, junto con las reformas políticas y económicas de la URSS (glasnost y perestroika) y por las restricciones más laxas a los traslados. En la antigua Yugoeslavia, el más abierto y desarrollado de los países socialistas, a los doctores rusos y ucranianos se les veía trabajando en los lugares de construcción durante sus vacaciones, mientras que las jóvenes mujeres de Ucrania eran explotadas en la industria del sexo. Finalmente, incluso antes de 1989, Polonia y Yugoeslavia tenían un perfil asociado con una importante emigración laboral hacia el occidente.

Los flujos migratorios en la región no sólo han estado configurados por las condiciones estructurales, las limitaciones del mercado de trabajo y financieras y las perspectivas de empleo que generan demanda y aportan mano de obra migrante de bajo costo en los países de origen y destino, sino también por la política étnica y los proyectos de construcción del Estado nacional postsocialista. ${ }^{5}$ Las guerras étnicas en la antigua Yugoeslavia derivaron en una nueva aprehensión en Europa occidental que se centraba en «la inundación» de refugiados y solicitantes de asilo desde principios de los años noventa. Los desafíos de la migración laboral y de los solicitantes de asilo del este al oeste desde países en crisis o en guerra no sólo desataron las discusiones en cuanto a un régimen migratorio común para toda Europa, sino que también fortalecieron la visión de una UE y su ampliación hacia el este.

\footnotetext{
5 Casi todos los estados en la región de Europa central y oriental, incluyendo los nuevos estados creados a raíz de la fragmentación de la Unión Soviética, tienen grandes comunidades de la diáspora en los países fronterizos: 1,2-2 millones de polacos viven en las ex repúblicas soviéticas, desde 1,6-6 millones húngaros viven predominantemente en Rumanía.
}

116 PRIMER SEMESTRE 2010 


\section{AMPLIACIÓN DE LA UE, EL DESAFÍO DE LA MOVILIDAD}

Y LAS AMBIVALENTES RESPUESTAS EUROPEAS

El comienzo de los años noventa se vio marcado por el triunfo del neoliberalismo sobre el comunismo. Una visión liberal de la UE como un mercado único se institucionalizó en el tratado de Maastricht en diciembre de 1991. El tratado, debido a la influencia británica, concedía escaso peso al Acuerdo Social para los Derechos Sociales de los Trabajadores (Social Charter for Basic Social Rights of Workers), que enfatizaba el diálogo social en el nivel macro y la democracia económica en el nivel de la empresa. Mientras que los acuerdos multilaterales, como el de Schengen, promovían la movilidad interna, los Estados-nación comenzaron a imponer de forma activa medidas más restrictivas para enfrentar los desafíos de la migración en general y de la migración irregular en particular. También consideraron necesario colaborar para hacer más rígidos los controles fronterizos, según fuera el carácter de emergencia y cada situación específica, al tiempo que se intensificaron el control y las sanciones para quienes dieran empleo o transportaran a migrantes irregulares (Ghosh, 1998). Proliferaron las iniciativas de migración en el nivel europeo, tanto en el Consejo de Europa como en la Comisión Europea de la Unión Europea (CE/UE) y la colaboración este/oeste con los países de la CEE evolucionó para controlar mejor los flujos migratorios.

A lo largo de la década de los noventa, los Estados trabajaron con denuedo por establecer los contornos del régimen de migración de la UE, levantando los muros de la «fortaleza Europa» a través del tratado de Maastricht, que más tarde se expandirían con el tratado de Roma, el decreto europeo único, la Convención de Dublín y el Acuerdo de Schengen. Según Michael Samers (2001), a contrapelo de la respuesta de política de Estados Unidos hacia la migración irregular y el desempleo, que ha estado más acorde con las necesidades de la acumulación económica y los diferentes grupos de cabildeo empresariales y étnicos, las respuestas europeas a las presiones de la migración han prestado mayor atención a los términos de la legitimación en términos de las preferencias de los electores y de las inquietudes de los sindicatos, más en los países del norte de Europa que en los del sur de ese continente.

De hecho, la preocupación por la legitimación política del proyecto de la integración europea en los Estados miembros llegó a ser particularmente estresante después de 1992, cuando los electorados en los Estados más importantes de Europa dieron un giro hacia los socialdemócratas, quienes salvaron a Europa de una reestructuración radical y disminuyeron las consecuencias sociales del neoliberalismo. Incluso en Estados Unidos y Gran Bretaña, en donde el thatcherismo y el reaganismo ejemplifican el dominio neoliberal, su impacto institucional ha sido reducido por los cambios en las preferencias electorales y por los procesos democráticos de los años noventa. Junto con las apabullantes victorias de los revigorizados demócratas en Estados Unidos, los socialdemócratas en toda Europa y, final- 
mente, el Nuevo Partido Laboral en Reino Unido, ha sido lanzada la búsqueda de una globalización socialmente sostenible y una dimensión social más pronunciada en la UE. El tomar en cuenta los temas sociales, como el desempleo, la pobreza, la desigualdad en el ingreso, diferentes formas de exclusión étnica y de género y la segmentación del mercado de trabajo, incluidos temas como el «trabajo indocumentado» y la migración, tuvieron como consecuencia la inclusión de metas de empleo en el Tratado de Ámsterdam celebrado en 1997. El tratado apoyó la Estrategia Europea de Empleo (EEE) y el lanzamiento del proceso de Luxemburgo en 1997, para ser puesto en práctica y derivar en el Pacto Europeo de Empleo en 1999, que suscribía una política de empleo dentro de las políticas de estabilidad macroeconómica. La cumbre de Luxemburgo en 1997 también endosó la quinta ampliación de la UE hacia los países de la CEE, al tiempo que diseñaba las sociedades de acceso como instrumentos de apoyo para los Estados solicitantes (Polonia, República Checa, Hungría, Eslovaquia, Latvia, Estonia, Lituania, Eslovenia, Bulgaria y Rumania) en el proceso de las negociaciones de la membresía.

Sin embargo, la inclusión de las preocupaciones sociales y de empleo en el Tratado de Ámsterdam y la subsiguiente subordinación de la EeE a las condiciones dadas por la estabilidad macroecónomica ejemplifica tan sólo el carácter contradictorio de los procesos de formación y ampliación de la UE, cargados de las conflictivas demandas de estabilización, eficiencia económica y competitividad, por un lado, y los objetivos de cohesión social y de legitimidad política, por el otro (Cf. Likic-Brboric, 2004; Schierup et al., 2006). Esto se ilustra en el discurso de «competitividad global» que sirvió de marco a la estragia de Lisboa en 2000 y que fuera presentado por la Cabeza de los Estados en la cumbre de Niza, quien endosó la Agenda de Política Social (CEC 2000) como un componente esencial en el apoyo de la competitividad. Su propósito fue "generar más y mejores empleos» y el desarrollo de una «economía con base en el conocimiento» por medio de una mayor movilidad, la «modernización» de la protección social y la promoción de la inclusión social, la igualdad de género y étnica, así como los derechos humanos.

De hecho, la estrategia de Lisboa y su puesta en práctica, influida fuertemente por el Nuevo Partido Laboral británico, así como por la política internacional marcada por el giro político de Estados Unidos hacia el conservadurismo a consecuencia de las tensiones posteriores al 11 de septiembre, han diluido las aspiraciones sociales de una mayor individualización política y económica, asociada con la transnacionalización del cambio de régimen europeo (Gowan, 2004). Las intervenciones en el nivel de la UE en el proceso de europeización del sistema de múltiples niveles en las relaciones industriales reflejan un acuerdo asimétrico entre los grupos de interés en competencia, lo que apoya un papel más fuerte para la Comisión, la acumulación de capital, el crecimiento económico, mientras que se prometen mejores "condiciones de vida y de trabajo» por medio de la flexibilización del mercado de fuerza de trabajo y de los regímenes de bienestar (Nieminen, 2001). En esencia, los ajustes a la estabilidad macroeconómica del mercado único 
y del capitalismo financiero anglosajón hasta el momento han sido «negativos» (Gowan, 2004:15). Han reforzado el poder del capital al tiempo que han debilitado a la fuerza de trabajo a través de la elevación de la competencia, la estabilización macroeconómica, la restricción fiscal y el fortalecimiento del euro. Según Gowan (2004:14), estas políticas no han generado una «construcción positiva de un nuevo conjunto de instituciones europeas en un régimen europeista unificado de acumulación» y han puesto en peligro los regímenes nacionales de acumulación en los principales estados miembros, Francia y Alemania. De igual manera, Apeldoorn (2003: 160) encuentra que el «orden socioeconómico europeo» trasnacional emergente puede designarse de mejor manera como un "neoliberalismo incorporado», dado que «subordina la región europea a las exigencias de la economía global y la competencia global y, por ende, a los intereses del capital global transnacional», al tiempo que, simultáneamente, reformula el proyecto neoliberal en términos de inclusión social con el objeto de lograr un consenso social más amplio en los Estados que tradicionalmente han sido corporativistas.

De hecho, esta dirección del proyecto de la ue hacia la creación del sistema capitalista global de producción y su reacomodo en términos de cadenas de producción globales, flexibles y «dirigidas por el comprador» (Gereffy y Kaplinski, 2001), no resulta inesperada si se toma en cuenta el hecho de que la UE se ha convertido en una de las más poderosas economías en el mundo, con la mayor porción de IED, con un 39\%, y la mayor parte de las exportaciones en el mundo (Berend, 2006). La entrada de China e India en el marco de la Organización Muncial del Comercio (OMC) y de las estrategias de las Corporaciones Trasnacionales (CTN) que utilizan la mano de obra barata por medio de la subcontratación y el empleo informal, muestran que la configuración del sistema de producción capitalista global tan sólo se hace por la creación paralela de un mercado global de fuerza de trabajo. Overbeek distingue tres mecanismos principales que han orientado los más recientes desarrollos hacia la creación de un mercado global de fuerza de trabajo, como el proceso de integración de «una proporción creciente de la población mundial hacia los mercados capitalistas de fuerza de trabajo» y encerrando a los «mercados de fuerza de trabajo nacionales y regionales dentro de un mercado de fuerza de trabajo global integrado». Éstos son: 1) la expansión del comercio y la producción transnacionales; 2) las nuevas formas de «mercantilización» global de la fuerza de trabajo, y 3) los patrones globales de migración laboral (Overbeek, 2003a: 17), y la UE ha participado activamente en su puesta en práctica.

La mercantilización de la fuerza de trabajo es, argumenta Overbeek, central para la configuración del sistema capitalista global. Implica la búsqueda de mano de obra barata a través de la integración de áreas previamente separadas (las economías que antes fueron socialistas y las economías en desarrollo) dentro del mercado capitalista mundial por medio de la «semiproletarización» e incluso la «mercantilización» de las actividades no mercantiles en las sociedades capitalistas avanzadas por medio de políticas de reestructuración, privatización y liberalización (Overbeek, 2003a: 19). 
Estos últimos procesos han derivado tanto en el crecimiento de los sectores informales como en la «remercantilización» de la fuerza de trabajo, las consecuencias de inhibir el carácter desmercantilizador del Estado de bienestar (Esping-Andersen, 1990). El proceso de «remercantilización» refleja las cambiantes relaciones de poder entre los actores sociales que se proponen alterar los arreglos institucionales existentes por medio de prácticas discursivas y de prácticas sociales que favorecen al capital y cosifican la fuerza de trabajo (Papadopoulos, 2005). De igual manera, (Slavnic, 2007) discierne las prácticas sociales de informalización «desde arriba» como significativas estrategias de los actores del Estado y los actores económicos para hacer progresar la contingencia a favor de la remercantilización por medio de una rápida estructuración de una segmentación dual y vertical del mercado de fuerza de trabajo.

Carl-Ulrik Schierup, Peo Hansen y Steven Castles (Schierup et al., 2006) también han abordado el incremento en los nuevos sectores informales en los contextos de las metropolis europeas. La informalización en las economías europeas avanzadas está entrelazada con una creciente segmentación étnica y de género del mercado de fuerza de trabajo, involucrando de manera considerable a las comunidades socialmente marginadas de inmigrantes y a los migrantes irregulares. En estas páginas, tales problemas se conciben como inherentes a las estrategias capitalistas globales de liberalización y desregulación, e implican a los actores corporativos que buscan la competitividad por medio de cadenas verticales de subcontratación. Estas cadenas vinculan a los Estados y a las regiones y difuminan la distinción entre actividades formales e informales y rescatan formas preindustriales de explotación de la fuerza de trabajo, junto con los talleres de trabajo intensivo (sweatshops) dentro de las economías del Primer Mundo. Sin embargo, como señalan Schierup, Hansen y Castles (2006), estos fenómenos se han extendido más en Gran Bretaña, como secuela de su trayectoria «neoamericana». El empleo informal de migrantes irregulares en la industria del vestido, el sector doméstico, el sector hotelero, la agricultura y la construcción se han convertido también en una importante estrategia empresarial en las economías del sur de Europa, Alemania y Holanda en el contexto del adelgazamiento del Estado, la polarización social, las inadecuadas provisiones de bienestar y el envejecimiento poblacional (Jordan y Düvell, 2002: 59-64).

Además, para el cambio del milenio, después del 11 de septiembre de 2001 y la crisis del sector de tecnologías de la información (TI), quedó claro que el aumento del desempleo en el sector industrial no ha sido enfrentado de forma adecuada por el incremento en los empleos de alta calidad en el sector de los servicios, incluidos TI, bancos, ventas al menudeo, biotecnología, educación y la más avanzada atención a la salud, como lo proyectaran los nuevos misioneros del nuevo conocimiento. Por el contrario, la expansión del sector de servicios de «alta calidad» se ha visto limitada, mientras que el aumento de la competencia en las ventas al menudeo, construcción y manufactura, adelgazamiento del Estado y la subsi- 
guiente privatización generaron una creciente demanda de fuerza de trabajo de escasa calificación en las ventas al menudeo, la hotelería y restaurantes, cuidado infantil y de personas ancianas. Además de la polarización social de las ciudades globales y una creciente migración indocumentada, que cubre la nueva demanda de trabajadores escasamente calificados, el trabajo doméstico y los servicios personales, hemos sido testigos de una expansión de la economía informal dentro de las economías industriales avanzadas en general (Overbeek, 2003a: 20), y en la UE en particular.

El principal efecto de esta dinámica ha sido la crisis del (o los) Estado(s) de bienestar como proveedor de empleos y de seguridad social, y una generación de la condición de exclusión social, problema que afecta predominantemente a las comunidades migrantes marginadas. Según Angus Cameron y Ronen Palan (2003) la exclusión social es resultado de la institucionalización de la «economía imaginada» y una reconstrucción relacionada de la «economía nacional» en apoyo del desarrollo de una «economía de deslocalización» (off-shore) y de una «economía privada» que generó la realidad de la "antieconomía», es decir, actividades económicas que resultan «no-competitivas». Bob Jessop identifica una respuesta común a la crisis del Estado de bienestar y a los problemas del desempleo y la exclusión social como un giro en proceso, intricado y dependiente de la trayectoria, desde diferentes tipos de modelos de "Estado nacional de bienestar keynesiano» ${ }^{6}$ hacia versiones diversas, nacionalmente matizadas de los «regímenes schumpeterianos de prestaciones sociales y contractuales condicionados (workfare) posnacionales» que implican la modificación de los regímenes sociales, laborales y de migración. Una crisis relacionaría la promoción schumpeteriana de la competitividad, la innovación y la flexibilidad y el espíritu empresarial a nivel sistémico, es decir, la articulación del régimen de prestaciones sociales y contractuales condicionados, ${ }^{7}$ dirigiría la política social a las necesidades de la competitividad nacional, la flexibilidad del mercado de fuerza de trabajo y la capacidad individual de conseguir empleo (empleabilidad/employability), y modificaría los servicios de bienestar y los derechos sociales de manera tal que beneficiaran los intereses empresariales. La búsqueda de una solución para las metas conflictivas del régimen de acumulación regional/global y el régimen nacional de bienestar social implica un «cambio desde la gobernación a la gobernanza», como un cambio de escala de la política del Estado, que se ejemplifica mejor por la actual configuración de la política de empleo y política social de la UE (Jessop, 2003: 34-41).

No obstante que las políticas de flexibilización y empleabilidad (employability) se tradujeron en la afirmación por parte de la Estrategia Europea de Empleo de

${ }^{6}$ El Estado de bienestar keynesiano se basa en un conjunto de políticas económicas y sociales que se conectaron a la ciudadanía social y se limita al Estado nacional, la economía y la sociedad. Se trata de la organización fordista de la producción y los distintos niveles de intervención estatal para resolver los problemas de fallas del mercado, la forma de la sociedad civil, entre ellos la búsqueda de «desmercantilización" del trabajo (Esping-Andersen 1990).

7 Workfare como opuesto a welfare, N. del T.). 
un mejoramiento de la inclusión social en general y de la acción en contra del racismo y la discriminación en particular, debilitan la posición en el mercado de fuerza de trabajo del creciente número ciudadanos de la ue con antecedentes de inmigración «quienes quedan atrapados en los ghettos ocupacionales del empleo casual y en las industrias del servicio posfordista y en los servicios municipales cada vez más desregulados» (Schierup, 2003:133). En combinación con un régimen fronterizo restrictivo en Europa, que genera un flujo de llegada de migrantes irregulares, junto con su mano de obra barata e indocumentada, el ajuste europeo a los desafíos sociales de las viejas y nuevas migraciones, requiere «la doble primera crisis de la rica Europa de la nación y del Estado de bienestar» en términos de la formulación de los derechos ciudadanos posnacionales (Schierup, 2003: 134). Para tal fin, con base en el Tratado de Ámsterdam, que enfatizó los derechos humanos fundamentales y la libertad, la CE ha intentado establecer políticas en contra de la discriminación, tanto a través de regulaciones «duras» como «suaves» (Soininen, 2003).

A pesar de ellos, las reconfiguraciones en múliples niveles de la nueva Europa "multiétnica», que tienen la intención de aumentar su "competitividad global», han generado múltiples dualidades que reflejan dilemas normativos no resueltos, que han de ser deliberados al nivel de la UE. La verdadera economía europea, marcada por la segmentación étnica y de género de los mercados de fuerza de trabajo, se ha tornado "multiexclusionaria» (Schierup, 2003: 133) y dependiente del continuo flujo de llegada de una fuerza de trabajo migrante, tanto de alta como de baja calificación. Acorde con el tratado de Ámsterdam, esta reflexión ha derivado en la reformulación del régimen de migración europeo, alejándolo de la «migración cero» hacia una administración «eficiente», «flexible» y hacia un control de la migración indocumentada por medio de un «transnacionalismo intensivo» (Samers, 2004). Antes del Consejo de Tesalónica en 2003, la Comisión presentó una comunicación sobre la inmigración ilegal, con fundamento en un trabajo preparatorio sobre el llamado Plan de acción de Santiago. Samers (2004) identifica tres principales características de este régimen emergente de política de inmigración: un cambio de escala, hacia arriba, y una «comunitarización gradual» del diseño de políticas, un cambio horizontal de escala en la seguridad en lo que respecta a terceros países y la creación discursiva de la inmigración ilegal como amenaza social. Peo Hansen (2005) afirma que estas articulaciones contradictorias del régimen de migración de la UE, que llevan la intención de lidiar con los sentimientos populistas anti-inmigración, debilitan las perspectivas de políticas en contra de la discriminación y erosionan claramente el derecho de asilo en el largo plazo.

La reciente y quinta oleada de ampliación europea y la inclusión de las sociedades poscomunistas, sin duda refuerza la informalización actual de las economías de la UE, a la vez que las presiones de los nuevos flujos migratorios. Aun cuando la más reciente oleada de ampliación no apoya los temores populares de un repentino y significativo flujo de llegada de migrantes, muchos trabajadores de los nuevos Estados miembros han estado involucrados en trabajo temporal de 
agencias, en especial en los sectores de la construcción y del trabajo doméstico. Aun cuando las cifras sobre migración se consideren como subregistros, según la OIM (IOM 2006: 145), tras la más reciente ampliación hacia el este, 730,000 ciudadanos de los nuevos Estados miembros de la UE y de los países candidatos a pertenecer a ella, han sido empleados con regularidad mediante los antiguos Estados miembros de la UE; 300,000 han tomado empleos regulares de temporada, mientras que se sospecha que un gran número, especialmente en el sector de la hospitalidad, cuidado del hogar y agricultura, todavía acceden a empleos irregulares, a pesar de la regularización de la residencia. Asumen salarios más bajos y aceptan condiciones laborales mucho peores, lo que promueve la flexibilidad del mercado de trabajo y una ue ampliada que se encuentra bajo el peso de la tendencia a la convergencia nominal. Aun cuando se incrementará la demanda de mano de obra en los nuevos Estados miembros de la UE, alimentada por dinero proveniente de fondos estructurales y de cohesión, en especial en los sectores de la construcción, el ambiente y el manejo de desechos, estos empleos no eliminarán los importantes factores de rechazo implicados en la migración del este al oeste, el desempleo estructural y las malas condiciones de trabajo. Probablemente, serán asumidos por migrantes irregulares provenientes de los nuevos Estados vecinos al este y de los países de la CIS, cuya condición irregular se genera por los nuevos controles fronterizos, pero también por parte de trabajadores provenientes de países en desarrollo distantes. Tomando en cuenta el hecho de que los nuevos Estados miembros también se han vuelto atractivos como destino de la inmigración y como países de tránsito, el flujo de entrada del nuevo tipo de inmigrantes indocumentados provenientes de, por ejemplo, China, Vietnam, India, Sri Lanka y Bangladesh, tienen que lidiar con los dobles desafíos de las tendencias migratorias regionales y globales. Al respecto, Krystyna Iglicka (2002: 208) sostiene que la ampliación y la puesta en práctica del régimen de Schengen deterioraran la precaria posición de los inmigrantes irregulares más vulnerables en los países de la CEE y pueden derivar en la explosión, tanto de xenofobia como de nacionalismo. De igual manera, Bettina Musiolek advierte de la avanzada informalización en los nuevos Estados miembros y en los países candidatos a acceder, debido al incondicionado compromiso de la UE con la «competividad global» y la tolerancia de las prácticas de las multinacionales por informalizar aún más los más lejanos extremos de la cadena de insumos y subcontratar con microempresas basadas en hogares. En ausencia de las instituciones adecuadas que eviten las faltas de respeto por los derechos humanos o las malas condiciones de trabajo, así como el discurso público que aborde de manera crítica las violaciones de las multinacionales a los derechos laborales y que genere una discusión adecuada en torno a las políticas sociales, es difícil poder presentar un frente opositor a las actitudes «dentro y hacia» la región que toleran la economía informal (Musiolek, 2002:12).

Pero la informalización no sólo se ve fortalecida por la nueva distribución geopolítica de la economía de la ue y una concomitante internalización de los resultados 
adversos de la transformación postsocialista a través de la integración política y económica que interconecta ahora estrechamente al oeste y al este. También se genera por una contradictoria instalación del libre movimiento de la fuerza de trabajo en los 27 países de la UE atravesando los antiguos 15 países miembros de la UE por medio de los arreglos restrictivos a la transición. Tomando en cuenta la creciente demanda de trabajadores de los nuevos Estados miembros, estas restricciones no imitan los traslados de mano de obra irregular ya existentes. Distorsionan la institucionalización de un mercado de fuerza de trabajo que opera como lo proyectaran los análisis económicos (Akkoynlu, 2001), aumentan la segmentación existente en el mercado, generan una situación irregular para los nuevos ciudadanos de la Ue y amplían el carácter casual de su empleo. Estos procesos conservan el «salario exprimido» y promueven la realidad de una «ciudadanía exprimida» que reduce la base socioeconómica de la identidad europea que se está construyendo. Las aproximaciones restrictivas a los trabajadores búlgaros y rumanos, incluso en países que en otros sentidos son liberales, como Irlanda y Gran Bretaña, ilustran los temores políticos de las respuestas nacionalistas populares ante las presiones de la competencia del mercado laboral y la mano de obra extranjera de bajo costo, sin enfrentar las políticas mismas de flexibilización del mercado de fuerza de trabajo per se.

Aunque la ue ha situado a la informalización de la economía y su nexo con la migración irregular y la ampliación de la UE como parte de su agenda, el problema ha sido conceptualizado como «trabajo no declarado» y como una amenaza a los servicios públicos. A partir de la aproximación legalista a la informalización, la CE ha promovido un enfoque de políticas armónicas, consistente en concesiones tributarias en los sectores en los que la competitividad se basa en el trabajo irregular, la responsibilidad de los patrones por la cadena de subcontratación y las campañas públicas por generar conciencia del problema. Las acciones en contra de la economía informal también se han convertido en parte de la eEE en 2003, implicando una coordinación laxa en las políticas, por medio de un proceso MAC (Mecanismo abierto de Coordinación) y de intercambio de información.

Estas iniciativas difícilmente pueden influir en la tendencia general hacia la informalización que es inherente a la preocupación primordial de la UE por el crecimiento económico y por bajar la inflación. Esta orientación limita las contingencias a favor del desarrollo y la emulación del Modelo Social Europeo, mientras que el bajo nivel de los salarios y la escasa protección social en los nuevos Estados miembros con las nuevas formas de casualización de la fuerza de trabajo-cum informalización permiten que continúen los «salarios exprimidos», la remercantilización y la segmentación vertical de la fuerza de trabajo en los antiguos Estados miembros. En busca de la «flexicuridad» el rediseño formal del modelo europeo orientado a la protección social se busca por medio de una laxa coordinación de políticas y un diálogo escaso en lo que respecta a la transformación de los regímenes del mercado nacional de fuerza de trabajo y de bienestar, 
también llamados «auto-transformación del modelo social europeo» (Hemerijck y Schludi, 2002: 105).

El centro de la economía política transnacional de la UE sigue siendo la configuración de un mercado global de fuerza de trabajo más allá del espacio nacional, aunque involucrando al mismo tiempo a los niveles nacional, internacional y subnacional. Overbeek (2003a) afirma que la ideología del neoliberalismo global ha sido adoptada incluso por los socialdemócratas y que la perspectiva de la UE ante la ampliación y las reformas al mercado de fuerza de trabajo como un factor primordial de la «competitividad» preparan claramente el camino para una mayor reestructuración por medio del despojo de los trabajadores. De la misma forma, la transformación del modelo social europeo dentro de estos parámetros implica claramente una caída del Estado de bienestar como la base institucional de la ciudadanía social. En el contexto de la UE, las políticas sociales y de migración se están tornando posnacionales, implicando la reasignación de la promoción de la justicia social universal a las articulaciones en los niveles globales, europeos, regionales, urbanos y locales. Al mismo tiempo, la puesta en práctica de las ya extensivas normas en torno a los derechos humanos, según fueron declaradas en las convenciones del Acta Social Europea o de la orT, se ha diluido por una «ambigüedad» relativa a la importancia del Acta de los Derechos Fundamentales para la integración Europea en la UE (McCrudden, 2001) y se ha reasignado a las redes públicas y privadas, regulaciones laxas e intercambios de metagobernanza entre el Estado y los actores no estatales en el nivel de la ue y en el nivel global (Jessop, 2003).

\section{LA GOBERNANZA GLOBAL, LA GLOBALIZACIÓN JUSTA Y LA AGENDA DEL TRABAJO DECENTE}

La administración de los procesos de globalización económica y sociocultural ha implicado un giro desde el gobierno a la gobernanza, con diversas recombinaciones de las respuestas institucionales comunes y aquellas referentes a países específicos y de las consecuencias políticas a lo ancho del planeta. La gobernanza global ha sido definida como «el conjunto de procesos y normas de carácter normativo, social, legal, institucional y de otros tipos que configuran y en algunos casos incluso regulan y controlan el interjuego dialéctico de la globalización y la fragmentación» (Clarke y Edwards, 2004:6). Sin embargo, los principales actores globales en la gobernanza primordial y, consistentemente, han navegado en el proceso de globalización hacia la creación de un régimen comercial liberal y hacia un sistema financiero y monetario asociado, encarnado en el establecimiento de la omc tras la ronda de Uruguay. Sin duda alguna, el sistema de gobernanza global y su agenda ha estado configurado, predominantemente por los países más poderosos y económicamente avanzados, en la OCDE, la organización de los países más desarrollados, encabezados por el G7, y han estado claramente dominados por Estados Unidos, así como por las corporaciones transnacionales. 
En este proceso de negociación del régimen global de comercio, la gobernanza global misma se ha visto reconfigurada. Las IFIs de Bretton Woods, específicamente el BM y el FMI, han sido instrumentales en la imposición del modelo neoliberal y en la promoción de la libre movilidad del capital. Con un fuerte apoyo de Estados Unidos y las economías avanzadas, las IFIs también han recibido una posición privilegiada, aparte de la arquitectura organizacional de la onU, un mandato claro y los recursos necesarios para promover una gobernanza global jerárquica, aislada de las inquietudes democráticas. A lo largo de la década de los noventa, el Bm endosó permanentemente al Consenso de Washington, incluyendo las reformas de política social a la baja y las leyes de flexibilización laboral, independientemente del creciente descontento con su déficit social y democrático, así como con el fracaso evidente para alcanzar el desarrollo económico y el empleo.

Sin embargo, al inicio del nuevo milenio, el «paradigma de Bretton Woods» $y$ su optimismo respecto a la erradicación de la pobreza en los países en desarrollo que adoptaran el comercio internacional impulsado por GATT/OMC (Thérien, 2005) ha sido cuestionado cada vez más. La alternativa, el «paradigma de la ONU» (Thérien, 2005), que está conformado por una concepción distinta del nexo entre la liberalización global y la pobreza, inequidad y deterioro de las condiciones sociales, los derechos humanos y laborales ha sido iniciado por varios fondos, comisiones y agencias afiliadas con el complejo y laxo esquema de la onu bajo el mecanismo de coordinación de Consejo Económico y Social (ECOSOC). Ello incluye el Programa de las Naciones Unidas para el Desarrollo (PNUD), la orT, el Fondo de Naciones Unidas para la Infancia (UNICEF) y el Alto Comisionado de las Naciones Unidas para los Derechos Humanos (ACNDH), en colaboración con la Organización Internacional para las Migraciones (OIM). Estas agencias multilaterales, dentro de sus traslapados mandatos orientados a promover el desarrollo humano, los derechos laborales y la justicia social, a lo largo de los años noventa elaboraron un amplio marco teórico y de políticas para la promoción de la dimension social de la globalización.

Tras la continuada negativa a incluir cláusulas sociales en las negociaciones de la OMC (Malmberg y David, 1998) y la ruptura en el diálogo de la globalización, en junio de 2000, la Asamblea General de la onu decidió comisionar a la OIT la tarea de formular una amplia estrategia de empleo global. La orT, dada la oportunidad dorada de restaurar su deteriorada posición en el marco de la gobernanza global, reafirmó su mandato de promover la justicia social por medio de forjar «una agenda para el trabajo decente», que fue formulada por su director general, Juan Samovia, en el Reporte sobre Trabajo Decente de 1999 (OIT, 1999). Según el reporte, el principal propósito de la OIT es «promover oportunidades para que mujeres y hombres obtengan un trabajo decente y productivo, en condiciones de libertad, igualdad, seguridad y dignidad» (OIT, 1999). La agenda a favor del trabajo decente corroboró el principio básico de la Constitución de la OIT, que postula la «desmercantilización» de la fuerza de trabajo y reafirma la Declaración sobre los Principios y Derechos Fundamentales en el trabajo de 1998, al tiempo que llama a respetar 
un conjunto de derechos humanos, sociales, económicos y culturales previamente declarados a nivel internacional. ${ }^{8}$

Además, el compromiso redivivo de la oIT para reafirmar y promover los estándares laborales también está relacionado con otros propósitos más ambiciosos, como la promoción del empleo, la protección social, el diálogo social y de seguridad, incluyendo las estrategias para lograr estos propósitos y dirigirse a todos los trabajadores, incluso los no regulados, los autoempleados y los que trabajan en el hogar. Además de estos ambiciosos propósitos, la agenda del trabajo decente trasciende la afirmación de un piso universal social de globalización económica. Cuestiona también la aproximación convectional al desarrollo y el crecimiento económicos globales, propone un acercamiento integrado al desarrollo sostenible y políticas macroeconómicas que reconocen los beneficios económicos de reducir el «déficit en el trabajo decente». En su reporte de 2001, el director general afirma que el trabajo decente es «rentable»y «factible», que necesita coherencia con el objeto de incluir objetivos tanto económicos como sociales, al tiempo que enfatiza su universalidad (orT, 2001).

En su intento por lograr estos propósitos, los expertos de la oIT han colaborado no sólo con los sindicatos, patrones y gobiernos, sino que también han abierto el diálogo con los movimientos sociales globales y con las onGs. A ello siguió una serie de reportes anuales y numerosos textos de discusión centrados en las diferentes facetas del empleo, las condiciones de empleo en proceso de deterioro y la pobreza. Uno de los reportes más significativos y críticos es el que lleva el título de Decent Work and the Informal Economy (El trabajo decente y la economia informal, OIT, 2002). La preparación y el endoso del reporte implicaron enérgicos y acalorados debates entre académicos, activistas feministas, onGs, así como sindicatos, gobiernos y patrones. ${ }^{9}$ Los principales temas consistieron en quién habría de representar a los trabajadores en la economía informal y cómo lograr la participación de las onGs, que ya trabajaban con los trabajadores informales en la orT, dado que los procedimientos de la orT operaban sobre la base de representaciones formales tripartitas que consistían en un grupo de trabajadores, patrones y gobiernos. La discusión también abordó la exigencia de cambio en los procedimientos para lograr la participación de las ongs que en realidad se abordaba en la enmienda adoptada en la

${ }^{8}$ La Declaración afirmó ocho convenios fundamentales que garantizaban la libertad de asociación, el reconocimiento de la negociación colectiva, eliminación del trabajo forzoso, prohibición del trabajo infantil, eliminación de la discriminación en el empleo y la ocupación y el derecho a la renta. Estos derechos también están vinculados a la Declaración Universal de los Derechos Humanos de 1948, el Convenio Internacional sobre Derechos Económicos, Sociales y Culturales de 1966 y la Declaración y compromisos de la Cumbre Mundial sobre Desarrollo Social de 1995.

9 El principal marco para la discusión y para el reporte se presentó por WIEGo (Woman in Informal Employment Globalizing and Organizing), una red global de investigación sobre políticas encabezadas por Marty Chen, un lector en la Kennedy School of Government, en la Universidad de Harvard. Otras organizaciones involucradas fueron IRENE (International Restructuring Education Network Europe), el Global Labour Institute, ICFTU (International Confederation of Free Trade Unions) y una docena más de ONGS y grupos de actividades que generaron reportes regionales y por país en el proceso preparatorio. 
sesión nonagésima de la orT en ocasión de la presentación del reporte sobre la economía informal.

El reporte afirmaba que una informalidad creciente, su complejidad y el hecho de que la mayor parte de los nuevos puestos de trabajo en los países en desarrollo y en transición se han generado dentro de la economía informal cuestiona el término «sector informal» como algo demasiado limitado. Se propuso un enfoque integral de la informalización y se presentó el término «economía informal» con el propósito de denotar la heterogeneidad del fenómeno, tomando en cuenta el empleo informal y las relaciones empresariales informales, incluyendo a la diversidad de actores: trabajadores y empresas que operan informalmente, como trabajadores por cuenta propia, vendedores ambulantes, limpiabotas, trabajadoras domésticas con pago en los hogares, trabajadoras en su hogar y en los talleres de trabajo intensivo dentro de cadenas productivas, las microempresas de autoempleados y sus empleados en la familia. Según la ort (2002: 2-3), estos grupos de actores comparten una condición en común que se manifiesta en la falta de reconocimineto y protección legales, una extrema vulnerabilidad y su dependencia respecto a compromisos institucionales informales que generan su propia «economía política» idiosincrática.

Un amplio marco para la perspectiva teórica se elaboró con base en la suposición de que la economía informal sólo puede entenderse en relación con la configuración de la economía formal y en el hecho de que los «déficits en el trabajo decente» ponen en peligro seriamente las condiciones de trabajo decente en la economía formal al generar presiones competitivas por medio de prácticas injustas. De acuerdo con ello, la oIT definió su propósito como la promoción del «trabajo decente a lo largo de un continuo que va del extremo informal al formal de la economía, y en formas orientadas al desarrollo, la reducción de la pobreza y equitativas para los géneros» (OIT, 2002: 4). La agenda de trabajo decente, como parte de una estrategia incluyente para retirar las causas profundas de la informalidad, consiste en cuatro módulos: generar oportunidades de empleo y de ingreso, mejora de los derechos en el lugar de trabajo, mejora de la protección social y fortalecimiento de la representación y la voz en la economía informal. Junto con el lanzamiento del reporte, en el diagrama 1 se identifican las metas, estrategias y los actores de mayor importancia.

En su búsqueda por lograr estos própósitos estratégicos y el objetivo organizacional más amplio de reinventarse a sí misma como un foro significativo para el diálogo sobre las políticas sociales, la ort lanzó otras varias iniciativas globales. Éstas han llegado a estructurar un discurso de justicia global, solidaridad y globalización justa, configuradas en torno al concepto de trabajo decente, marcos cognitivos y normativos diferentes en apoyo a políticas alternativas dirigidas a una reconfiguración discursiva del orden global. ${ }^{10}$ En el nivel más alto, la ort lanzó la Comisión Mundial sobre la Dimensión Social de la Globalización (WCSDG-World

${ }^{10}$ Una lucha hegemónica gramsciana para la reconfiguración ideológica del orden político del discurso y su institucionalización, según propone Fairclough (Fairclough 1992; Likic-Brboric 2003). 
Estrategias y actores que promueven la agenda del trabajo decente

\begin{tabular}{|c|c|}
\hline PROPÓSITOS Y ESTRATEGIAS & ACTORES SIGNIFICATIVOS \\
\hline $\begin{array}{l}\text { Ratificación y puesta en práctica de los más impor- } \\
\text { tantes estándares laborales y del derecho a organi- } \\
\text { zarse. } \\
\text { Promoción del espíritu empresarial y de pequeñas } \\
\text { empresas. } \\
\text { Esquemas de movilidad y políticas de mercado de } \\
\text { trabajo activas, incluidos el desarrollo de habilida- } \\
\text { des y educación. } \\
\text { Microfinanzas. } \\
\text { Esquemas de protección social. } \\
\text { Seguridad y salud en el trabajo. } \\
\text { Inclusión de estándares laborales del trabajo infor- } \\
\text { mal en la planeación urbana. }\end{array}$ & $\begin{array}{l}\text { Nacionales } \\
\text { - Empleados informales, patrones y propietarios de } \\
\text { empresas informales. } \\
\text { - Gobiernos centrales y locales, inspectores labora- } \\
\text { les y autoridades impositivas, sindicatos, ONG's y } \\
\text { empresarios formales y sus asociaciones. } \\
\text { Internacionales } \\
\text { - La OIT. } \\
\text { - Comisión y Parlamento de la UE. } \\
\text { - Organizaciones con fundamento en la ONU. } \\
\text { - Grandes CTN's y patrones extranjeros. } \\
\text { - Organizaciones internacionales y sindicatos de la } \\
\text { UE, redes sociales globales. }\end{array}$ \\
\hline
\end{tabular}

Commission on the Social Dimension of Globalization) que produjo su reporte final, A Fair Globalization, en 2004. El reporte se ocupa del impacto de la globalización y propone un marco inclusivo para una gobernanza global justa con el objeto de equilibrar las instituciones financieras y económicas globales, liberar los flujos de capital y financieros, con una base social universal, derechos humanos y laborales y reglas justas para el traslado transfronterizo de personas (WCSDG, 2004). Otra iniciativa concierne a la migración como fenómeno global y la construcción del Grupo de Migración Global (GMG-Global Migration Group) junto a la orm y otras varias agencias de la onU e iniciativas de ésta, complementarias en el campo de la migración. El secretario de la onu lanzó también la Comisión Global para la Migración Internacional (GCIM-Global Commission on Internationa Migration) que presentó su reporte en 2005 (GCIM, 2005). El reporte exploraba algunos de los problemas de lo global en la migración, en especial el cálculo de la creciente migración indocumentada y reafirmaba los mecanismos legales existentes que habrán de enmarcar las políticas de migración.

Es claro que todas estas iniciativas presentan un formidable trabajo burocrático y un ejercicio discursivo, pero la posibilidad de poner en práctica visiones alternativas que tomen a la justicia social en términos de los derechos de los trabajadores también debe discutirse dentro de una perspectiva histórica y debe analizarse dentro de la economía política internacional, entendida como «economía geopolítica» que reclama el papel del Estado nación para configurar la globalización en general y la migración global en particular (Samers, 1999). En su conjunto, los discursos sobre la migración han evidenciado la distancia existente entre los argumentos y los análisis desarrollados dentro de la «perspectiva de los derechos» y de la "perspectiva económica» sobre migración. En ambas, se espera que la libre migración tenga efectos positivos en el crecimiento económico, tanto de los países de origen como de los receptores, reduciendo de esa forma las inequidades globales en el largo plazo, al tiempo que promovería los derechos de 
ciudadanía transnacionales. Sin embargo, las desviaciones en el término corto y mediano, la creciente migración irregular y la informalización de la economía conllevan desafíos sociales y políticos, así como costos sociales del ajuste que se articulan como conflictos sociales, racismo y xenofobia, si no se les atiende adecuadamente. La presión hacia la baja, que ha generado la migración irregular en los salarios y el deterioro de las condiciones de trabajo, requieren claramente una exploración de las múltiples facetas de las consecuencias de la migración internacional. Por ejemplo, en el contexto de la globalización y del tratado de libre comercio regional, el TLCAN, las crecientes desigualdades en el ingreso en la economía de Estados Unidos y casi tres décadas de "estrechamiento del salario» y el deterioro en los diferenciales de salarios para la mano de obra no calificada se atribuyen a la migración y al libre comercio. En contra de las teorías económicas (teoría de Heckscher-Ohlin-Mundell) que predicen que una menor migración en el contexto del libre comercio y la libre movilidad del capital, los estudios sobre la migración internacional apuntan hacia una correlación positiva entre el libre comercio y el aumento en la migración internacional (Solimano, 2001). Esta «paradoja de la migración» ha de analizarse junto con los estudios críticos del desarrollo que señalan otras discrepancias entre las expectativas optimistas que se derivarían de la liberalización y las políticas de desregularización que están informadas por la economía dominante y su impacto económico verdaderamente desilusionante.

Debido a estos escenarios globales optimistas y de laissez faire, la ort ha tenido dificultades para promover y establecer cláusulas sociales y estándares laborales como norma efectiva dentro del régimen de comercio internacional (Malmberg y David, 1998). De hecho, ya existe una plétora de reglas internacionales, normas e instrumentos regionales para constituir una perspectiva con base en los derechos humanos en la migración en general, y a la migración laboral e irregular en particular, que podría, si se pusiera en práctica, proteger a los migrantes frente a las peores formas de explotación y de tráfico de personas (Convenciones 97 y 143 de la OIT) al tiempo que garantizarían el respeto por derechos de los migrantes siguiendo la Convención Internacional sobre la Protección de los Derechos Humanos de todos los Trabajadores Migrantes y sus Familias. ${ }^{11}$ Sin embargo, estas declaraciones, convenciones y recomendaciones universales han resultado insuficientes, dado que no están apoyadas por sanciones efectivas. Algunos estudios de la articulación de un régimen internacional y su base normativa incluso han señalado el efecto debilitador de la plétora de estándares e instrumentos paralelos que reflejan la competencia organizacional dentro del sistema de la onU (Ghosh, 1998; Hasenau, 1990).

Otro problema está relacionado con la estrategia transnacional y con la capacidad organizativa de los actores multilaterales fuera del Estado, los sindicatos,

${ }^{11}$ Llevó doce años que se adoptara y más de una década para que se le ratificara por parte de los países miembros necesarios para que entrara en vigor.

130 PRIMER SEMESTRE 2010

MIGRACIÓN Y DESARROLLO NÚM. 14 
las ONG's internacionales, las comunidades académiccas y la sociedad civil en su conjunto, para generar una diferencia significativa. Se han seguido básicamente dos rutas de acción: una orientada hacia el fortalecimiento del poder del «precariedado» y otra a lo largo de la gobernanza de la cadena de producción de valor, en donde se enfatiza el papel de las agencias multilaterales, cTNs y el Estado. Respecto a las primeras, se ha dado una división entre los sindicatos y las onGs. Los sindicatos, por un lado, fueron criticados por el estilo burocrático, el nacionalismo y la exclusión de los pobres y excluidos, mientras que se les alabó su capacidad organizativa y su democracia interna (Cf. Silverman, 2005). Sin embargo, la movilización reciente de los sindicatos en contra de la criminalización de los inmigrantes ilegales en manifestaciones en todo Estados Unidos, apunta hacia un cambio en sus prácticas y actitudes. Por otra parte las onGs fueron alabadas por su organización fluida, mientras que se les criticó su falta de coordinación y por centrarse en una reducción de la pobreza que deja de lado el tema del empleo (Eade y Leather, 2004). ${ }^{12}$ El problema, empero, ha sido abordado por la red de investigación de WIEGO en un manual de políticas, Mainstreaming Informal Employment and Gender in Poverty Reduction (Chen et al., 2004). Otra iniciativa ha sido lanzada por la Plataforma para la Cooperación Internacional en torno a los Migrantes Indocumentados (PICUM-Platform for International Cooperation on Undocumented Migrants), una ONG de amplio espectro ubicada en Bruselas. El reporte «Diez maneras de proteger a los trabajaores migrantes indocumentados», hace un llamado a que los sindicatos y los grupos cívicos se comprometan con la promoción de los derechos humanos y laborales de los trabajadores migrantes indocumentados y a su dotación de poder (empowerment) por medio de la reformulación de las políticas de integración de la UE y la Estrategia Europea de Inclusión Social (Picum, 2005).

Respecto a la última, una estrategia dirigida a desarrollar la responsabilidad corporativa y la participación del Estado, ha sido generada a partir de una investigación innovadora que identificaba la «desigualización» por medio de cadenas de producción globales jerárquicamente organizadas, sus tendencias y resultados distributivos poco favorables (Gereffy y Kaplinski, 2001; Kaplinsky, 2000). Finalmente, pero no de menor importancia, las iniciativas como las que conlleva el lanzamiento de las campañas de responsabilidad social corporativa y de comercio justo, incluida la práctica de las condiciones sociales pendientes en los acuerdos de comercio bilaterales y regionales.

Los más importantes actores, las CTNs, los Estados nacionales y los actores regionales, en su mayor parte, han promovido las inicitivas de comercio justo, al mismo tiempo que se muestran menos entusiastas en la promoción de la agenda del trabajo decente. Aun cuando muchos gobiernos apoyan formalmente la agenda, el problema de la puesta en práctica ha sido replanteado en términos de gobernanza, entendida como conjuntos formales e informales de instituciones y políti- 
cas que establecen el interjuego entre la sociedad y la economía, pero sin ninguna acción resuelta del gobierno. Los expertos de la orT se han empeñado en la difusión de los estándares de trabajo internacionales en diferentes contextos nacionales a través de programas piloto sobre el trabajo decente, pero la revisión reciente requiere una «visión mucho mas proactiva» (OIT, 2005).

\section{LA AGENDA DEL «TRABAJO DECENTE»Y LAS CONTINGENCIAS PARA UNA UE AMPLIADA}

La UE y sus Estados miembros son los actores más significativos en la configuración del régimen económico global dentro del marco del multilateralismo. En ese proceso, la un ha comunicado con cautela su apoyo a diferentes iniciativas globales por avanzar la dimensión social de la globalización y por atender los temas de la justicia social. Ha apoyado el cambio de escala y la transnacionalización de la promoción de la dimensión social de la globalización y la agenda de «trabajo decente» de la orT. Por ejemplo, en 2001, la Comisión Europea expresó su apoyo para el avance de los estándares laborales centrales y de las acciones de políticas dirigidas a fortalecer su aplicación eficiente. Estas acciones incluyen una mayor discusión dentro del marco de la ort y la inclusión de estos temas en el discurso del desarrollo global, apoyo a la asistencia técnica de la orT, la entrada de estándares laborales en el sistema generalizado de preferencias, las relaciones bilaterales y los acuerdos comerciales, responsabilidad corporativa, etiquetas sociales y códigos de conducta, pero en cambio un «rechazo a las aproximaciones basadas en sanciones dentro de la política de comercio» (CEC, 2001). En 2004, la Comisión respondió al reporte de WCSDG conformándose con la preocupación respecto a los aspectos negativos de la globalización y una necesidad de promover la dimensión social de la globalización, tanto dentro del contexto europeo como en el contexto global. En su comunicación (CEC, 2004), la Comisión enfatizó los aspectos sociales de la estrategia de Lisboa, la importancia del diálogo social, los fondos estructurales y el Fondo Social Europeo para aminorar las consecuencias de la rápida reestructuración y la promoción del capital humano y la «empleabilidad» en los nuevos Estados miembros (previamente la CEE). Sin embargo, la significancia del Modelo Social Europeo, los instrumentos y métodos de política que apoyan la faceta social de la europeización se ve reducida al aludir al «resto», es decir, a los otros países en transición en la cercanía y a los terceros países. Estos habrían de ser apoyados por la nueva Política de Vecindad Europea o por la política de desarrollo dominante, configurada en las Metas de Desarrollo del Milenio, los derechos humanos y la democratización. En todas estas comunicaciones, el principal propósito e instrumento de promoción de la dimensión social continúa siendo el libre comercio, incluyendo los tratados bilaterales, la responsabilidad corporativa y las iniciativas sociales privadas, mientras que los problemas de los efectos sociales de la globalización habrían de abordarse por medio de iniciativas de investigación. El tema de 
la migración se ha referido tan sólo en un paréntesis y se le ha asignado a los foros multilaterales.

Aun cuando la Confederación de Sindicatos Europeos (ETUC-European Trade Union Confederation) ha convocado persistentemente a un compromiso más activo de la ue con la "agenda del trabajo decente», como se manifiesta en el intercambio de cartas entre la EC y la OIT en 2001, estos temas apenas comenzaron a ser atendidos seriamente en 2006. Parece que Bob Deacon (2005) predijo correctamente el cambio en el discurso de la globalización hacia una consideración más seria de las políticas sociales universales. El debate acerca de la globalización parece haberse restringido a una preocupación común por las desventajas de la globalización, como el aumento en la inequidad y la debilitada clase media, incluso en el mundo desarrollado. El más ardiente promotor de la globalización, Martin Wolf (2007), por señalar alguno, ha argumentado, tanto en el Foro Económico de Davos como en su columna en el Financial Times, en torno a la necesidad de traer nuevamente al Estado de bienestar. De tal forma, la comunicación de la Comisión (CEC, 2006), preparada en conjunto por los directores generales de empleo y asuntos sociales, de relaciones exteriores, y de desarrollo y comercio, parece reflejar «el espíritu del momento». La Comisión enfatiza su fuerte influencia en la reconfiguración de la globalización por medio de la inclusion de la «agenda del trabajo decente» como un «noveno propósito de desarrollo del milenio» dentro de sus políticas externas, incluidas la políticas de ampliación, de vecindad y de cooperación para el desarrollo. Además, promete promover una «mejor administración de la migración económica» a partir de la experiencia previa de la puesta en práctica del libre traslado de trabajadores, sus derechos e integración dentro de la UE. Sin embargo los actores de la sociedad civil, como el EurActive han expresado sus críticas por la falta de atención al deterioro de los estándares laborales dentro de la ue y los países candidatos (EurActiv, 2006).

En su estudio exploratorio de la economía informal en la región de CEE/CIS, Bettina Musiolek (2002) señaló las políticas de Estado de desregulación dirigidas a atraer la IED como los principales obstáculos para la promoción de la «agenda del trabajo decente». Tomando en cuenta los sentimientos nacionalistas en los países de la CeE y la falta de experiencia, instituciones y capacidad para la administración de la migración con base en los derechos humanos, así como para la interacción y la integración de los inmigrantes en las sociedades locales, queda claro que los nuevos Estados miembros requieren recursos económicos, instrumentos políticos y una base normativa para el reconocimiento y protección de los derechos de los trabajadores migrantes y de las condiciones de trabajo decentes incluso para los trabajadores en la economía formal. Apenas recientemente la oficina regional en la CEE de la ICFTU ha iniciado el proceso para la inclusión de los trabajadores en la economía informal. En ello reconocen obstáculos en su propia debilidad organizacional, una dependencia enorme en la economía informal, tanto en los sectores privados 
como estatales, y la ambivalencia de los estados de la CEE para regularizar y formalizar la economía informal (Glovackas, 2005).

De tal modo, a pesar de las intervenciones discursivas en apoyo de la justicia social y la formalización, hemos visto la práctica de una más marcada polarización económica y social, la informalización de la economía y una creciente migración irregular, es decir, las articulaciones de una economía política regional y global de la inequidad. El impacto real de la actual articulación del consenso global y de la ue en apoyo de la inclusión de la justicia social en la globalización y la europeización sigue dependiendo de su traducción en contextos nacionales de política, por un lado, y de las limitaciones que se derivan de la incondicional devoción de los Estados desarrollados por las negociaciones de la OMC y por la competividad mundial, que cuidadosamente ponderan la inclusión de las condiciones sociales, tan sólo en la medida en que faciliten evitar el proteccionismo económico.

En última instancia, el principal obstáculo a la promoción de la «agenda del trabajo decente» y de los derechos de los migrantes en el contexto de la ampliación de la UE sigue siendo la ambivalente política de Estado y las concepciones problemáticas asociadas de la migración irregular como un tema humanitariano o de libre tránsito, por un lado, o como un problema de distorsión del mercado laboral global, por el otro, sin reconocer a los migrantes irregulares como actores sociales (Termonen, 2004). Con el objeto de abordar y regular los problemas generados por la política de libres flujos de capital y un (menos) libre flujo de personas de la UE, necesitamos forjar una noción de la ciudadanía europea que incluya una «concepción sustantiva de la membresía política para los inmigrantes así como para los ciudadanos marginados y las personas pobres en los países del mundo rico» (Sassen, 2006). Tal empresa requiere la formulación de la «política de la propincuidad y de la conectividad» que adopta el respeto y la «responsabilidad» tanto para el otro que está próximo como para el «otro distante» (Stenning, 2005). También exige «la descolonización de las geografías europeas» (Pickles, 2005) y una concepción de las transformaciones poscomunistas como un elemento central de la europeización que afecta igualmente tanto al este como al oeste.

\section{BIBLIOGRAFÍA}

Akkoynlu, S. (2001), «European Labour Markets: Can Migración Provide Efficiency? The Polish-German Case», Working Paper, Canterbury, Department of Economics, University of Kent at Canterbury.

Apeldoorn, B.V. (2003), «The Struggle over European Order: Transnaciónal Class Agency in the Making of "Embedded Neo-Liberalism»", en N. Brenner, B. Jessop, M. Jones y

G. MacLeod (eds.), State/Space: A reader, Oxford, Blackwell Publishing.

Ardittis, S. (ed.) (1994), The Politics of East-West Migración, London, The Mac Millan Press Ltd.

134 PRIMER SEMESTRE 2010

MIGRACIÓN Y DESARROLLO NÚM. 14 
Berend, I.T. (2006), An Economic History of Twentieth Century Europe, Cambridge, Cambridge University Press.

Boughton, J.M. (2001), Silent Revolution: The Internaciónal Monetary Fond 1979-1989, Washington DC, International Monetary Fond.

Cameron, A. y R. Palan (2003), "The Imagined Economy: Mapping Transformations in the Contemporary State», en N. Brenner, B. Jessop, M. Jones y G. MacLeod (eds.), State/ Space: A Reader, Oxford, uK, Blackwell Publishing.

Campbell, J.L. y O.K. Pedersen (2001), "Conclusion: The Second Movement in Institutional Analysis», en J.L. Campbell y O.K. Pedersen (eds.), The Rise of Neoliberalism and Institutional Analysis, Princeton, Princeton University Press.

Castells, M. y Portes, A. (1989), «World Underneath. The Origins, Dynamics, and Effects of the Informal Economy», en A. Portes, M. Castells y L.A. Benton (eds.), The Informal Economy: Studies in Advances and Less Developed Countries, Baltimore y Londres, The John Hopkins University Press.

CEC (2000), «Social Policy Agenda», Brussels.

(2001), «Promoting Core Labour Standards and Improving Social Governance in the Context of Globalization», Bruselas.

(2004), «The Social Dimension of Globalization-the EU's policy contribution on extending the benefits to all», Bruselas (18.5.2004).

(2006), «Promoting decent work for all. The EU contribution to the implementatio of the decent work agenda", Bruselas (24 de mayo de 2006).

Chavdarova, T. (2002), "The informal economy in Bulgaria: historical background and present situación», en R. Neef y M. Stanculescu (eds.), The Social Impact of Informal Economies in Eastern Europe, Burlington, Ashgate.

Chen, M.A., Vanek, J. y Carr, M. (2004), Mainstream Informal Employment and Gender in Poverty Reduction, A Handbook for Policy-makers and Other Stakeholders, Londres, The Commonwealth Secretariat.

Clarke, J.N. y G.R. Edwards (2004), «Introduction», en J.N. Clarke y G.R. Edwards (eds.), Global Governance in the Twenty-First Century, Houndmills, Basingstoke y Nueva York, Palgrave MacMillan.

Deacon, B. (2005), «From «Safety Nets» Back to «Universal Social Provision»», Global Social Policy 5, pp. 19-28.

EADE, D. y A. Leather (eds.) (2004), Trade Unions and NGO Relaciones in Development and Social Justice, Development in Practice.

Esping-Andersen, G. (1990), The Three Worlds of Welfare Capitalism, Oxford, Polity Press. EurActiv (2006), "Commmission to Promote decent work' in the world», http//www. euractive.com/en/social europe/commission-promote-decent-work-world/archive

FairClough, N. (1992), Critical Discourse Analysis, Londres, Longman.

GCIM (2005), «Migration in an interconnected world: New directions for actions».

Gerefry, G. y Kaplinski, R. (eds.) (2001), The Value of Value Chains.

Grosh, B. (1998), Huddled Masses and Uncertain Shores. Insights into Irregular Migration, La Haya, Martinus Nijhoff Publishers.

GlovaCKaS, S. (2005), "The Informal Economy in Central and Eastern Europe», Ginebra, Global Labour Institute, http://www.global-labour.org/glovackas.htm 
Goldman, R., Papson, S. y Kersey, N. (1998/2003), «Landscapes of Capital», http://it.stlawu.edu/ global/

Gordon, D.M. (1996), Fat and Mean. The Corporate Squeeze of Working Americans and the Myth of Managerial Downsizing, Nueva York y Londres, Martin Kessler Books The Free Press.

Gowan, P. (2004), "The Politics of the Regime Shaping in the EU», Research Seminar Series DESTIN, http://www.crisisstates.com/download/seminars/Gowan.pdf

Hansen, P. (2005), «A superabundance of contradictions: The European Union's Post-Amsterdam Policies on Migrant «Integration», Labour Immigration, Asylum, and Illegal Immigration", Ocasional Papers and Reprints on Ethnic Studies, Linköping, Centre for Ethnic and Urban Studies, Linköping University.

Hasenau, M. (1990), «Setting Norms in the United Nations Systems: The Draft Convention on the Protection of Rights of All Migrants and Their Families in Relation to ILO Standards on Migrants Workers», International Migration 28, pp. 133-158.

Hollingsworth, R.J. (2002), «Social Systems of Production and Beyond», en R.J. Hollingsworth, K.H. Müller y E.J. Hollingsworth (eds.), Advancing Socio-Economics. An Institutional Perspective, Lanham New York Oxford, Rowman \& Littlefield Publishers, Inc.

IGLICKA, K. (2002), «Towards Converging Migratory Trends in Europe», The Brown Journal of World Affairs, 8, pp. 203-210.

ILO (1999), «Decent Work: Report of the Director-General to the 87th Session of the Internaciónal Labour Conference», Ginebra.

(2001), «Reducing the Decent Work Deficit. A global challenge. Report of the Director General to the 89th Session of the Internaciónal Labour Conference», Ginebra. (2002), «Decent work and the informal economy. Report VI to the 90th Session of the International Labour Conference», Ginebra, ILO.

(2005), «Decent Work and a Fair Globalization: National Policy Responses», Ginebra, http://training.itcilo.org/decentwork/StaffConf2005/resources/turinreport.pdf IOM (2006), «World Migration 2005», World Migración Report, Ginebra, International Organization for Migration.

Jessop, B. (2003), "Changes in welfare regimes and the search for flexibility and employability", en H. Overbeek (ed.), The Political Economy of European Employment: European Integración and the Transnaciónalización of the (Un)employment Question, Londres, Routledge. JoRDan, B. y Düvell, F. (2002), Irregular Migración. The Dilemmas of Transnational Mobility, Cheltenham, UK, Edward Elgar.

KapLINSKY, R. (2000), "Globalization and Unequalization: What Can Be Learned from Value Chain Analysis?», IDS Working Paper 100.

King, R. y Rybaczuk, K. (1993), «Southern Europe and the international division of labour: from emigración to immigración», en R. King (ed.), The new geography of European migraciones, Londres y Nueva York, Belhaven Press.

Lavigne, M. (1999), The Economics of Transition. From Socialist Economy to Market Economy, Nueva York, St. Martin Press.

Likic-Brboric, B. (2003), Democratic Governance in the Transition from Yugoslav Self-Management to a Market Economy. The Case of the Slovenian Privatización Debates 1990-1992, Uppsala, Uppsala University.

136 PRIMER SEMESTRE 2010

MIGRACIÓN Y DESARROLLO NÚM. 14 
(2004), "Creating a Stable Flexibility in an Enlarged Europe», en B. Likic-Brboric, y S. Murhem (eds.), The Challenge of Industrial Restructuring, Bruselas, Work Life and eu Enlargement, Uppsala University.

MalmberG, J. y David, J. (1998), «Social Clauses and Other Means to promote Fair Labour Standards in International For a», Arbetslivsrapport, Stockholm, Arbetslivsinstitutet. MCCrudden, C. (2001), "The Future of the EU Charter of Fundamental Rights», Jean Monnet Working Paper, Nueva York, New York University School of Law.

Milanovic, B. (2003), «The Two Faces of Globalization: Against Globalization as We Know It», World Development 31, pp. 667-683.

Musiolek, B. (2002), «Decent Work in the Informal Sector Cee/CIs Region», Ginebra, International Labour Office.

Neef, R. (2002), "Observation on the concept and forms of the informal economy in Eastern Europe», en R. Neef y M. Stanculescu (eds.), The Social Impact of Informal Economies in Eastern Europe, Burlington, Ashgate.

Nieminen, A. (2001), «A Multi-Level System of the EU's Industrial Relations: Dynamics and Social Meaning», European Sociological Associación's Fifth Conference, University of Helsinki, Finland, http//www.helsinki.fi/ arniemin/m_level.htm (2005-10-23).

Nordstrom, C. (2003), «Shadows and Sovereigns», en N. Brenner, B. Jessop, M. Jones y G. MacLeod (eds.), State/Space: A Reader, Oxford, UK, Blackwell Publishing.

Overbeek, H. (2003a), «Globalization, neo-liberalism and employment question», en $\mathrm{H}$. Overbeek (ed.), The Political Economy of European Employment. European integratio and transnaciónalization of the (un)employment question, Londres y Nueva York, Routledge Taylor \& Francis Group.

(2003b), "Transnational political economy and the politics of European (un)employment», en H. Overbeek (ed.), The Political Economy of European Employment. European integración and transnaciónalización of the (un)employment question, Londres y Nueva York, Routledge Taylor \& Francis Group.

Papadopoulos, T. (2005), «The Recommodification of European Labour: Theoretical and Empirical Explorations», en ERI (ed.), Working Paper Series WP-05-03, The University of Bath, The European Research Institute (ERI), http://www.bath.ac.uk/eri/ERI-working-papers/ERI-working-paper-05-03-final.pdf

PAtZWaldt, K. (2004), «Labour Migración in Eastern Europe and Central Asia and Next Political Steps", UNESCO Series of Country Reports on the Ratification of the UN Convention on Migrants, UnesCo.

Peterson, S.W. (1994), Silent Depression. Twenty-five Years of Wage Squeeze and Middle-Class Decline, Nueva York y Londres, W.W. Norton \& Company.

PickLes, J. (2005), «New cartographies» and the decolonización of European geographies», Area 37, pp. 355-364.

PICUM (2005), «Ten Ways to Protect Undocumented Migrant Workers», Bruselas, Picum (Platform for International Cooperation on Undocumented Migrants), www.picum.org Putzel, J. (2005), «Globalization, Liberalization, and Prospects for the State», International Political Science Review 26, pp. 5-16.

Sachs, J.D. (2005), The End of Poverty. Economic Possibilities of Our Time, Londres, Penguin Books. 
SAmers, M. (1999), «"Globalization», the geopolitical economy of migration and the "spatial vent», Review of International Political Economy 6, pp. 166-199.

(2001), «Here to Work»: Undocumented Immigration in the United States and Europe», SAIS Review XXI, pp. 131-145.

(2004), «An Emerging Geopolitics of «Illegal» Immigration in the European Union», European Journal of Migration and Law 6, pp. 27-45.

SASSEn, S. (1988), The Mobility of Labour and Capital: A Study in International Investment and Labour Flow, Cambridge, UK, Cambridge University Press.

(1998), Globalization and Its Discontents: Essays on the New Mobility of People and Money, Nueva York, The New Press.

(2006), «Migration policy: from control to governance», Open Democracy, www. openDemocracy.net

(1989), «New York City's Informal Economy», en A. Portes, M. Castells y L.A.

Benton (eds.), The Informal Economy: Studies in Advanced and Less Developed Countries, Baltimore y Londres, The John Hopkins University Press.

Schierup, C.U. (2003), «Migración, Ethnic Divisions and Dimensions of Social Exclusion:

The Relevance of United States Theories for European Research", en E. Zeybekoglu y B. Johansson (eds.), Migration and Labour in Europe. Views from Turkey and Sweden, Estambul, Marmara University Research Center for International Relations and Swedish National Institute for Working Life.

P. Hansen y S. Castles (2006), Migration, Citizenship and the European Welfare State.

A European Dilemma, Oxford, Oxford University Press.

Silverman, N.A. (2005), «Deserving Decent Work: The complicatios of Organizing Irregu-

lar Workers Without Legal Rights», COMPAS Working Papers, Oxford, University of Oxford.

Slavnic, Z. (2007), «Informalization of the Economy and the Recommodification of Labour», en Erik Berggren, B. Likic-Brboric, G. Toksöz y N. Trimikliniotis (eds.), Irregular Migration, Informal Labour and Community in Europe, Maastricht, Shaker Publishing. SoIninen, M. (2003), «Exploring EU Ethnic Diversity and Anti-Discrimination Policy», en E. Zeybekoglu y B. Johansson (eds.), Migration and Labour in Europe. Views from Turkey and Sweden, Estambul, Marmara University Research Center for International Relations and Swedish National Institute for Working Life.

Solimano, A. (2001), "Global Migration and the Global Economic Order: An Overview», Policy Research Working Paper, Washington DC, The World Bank.

Sото, H. de (1989), The Other Path. The Economic Answers to Terrorism, Nueva York, Basic Books. Standing, G. (1989), «The «British Experiment»: Structural Adjustment or Accelerated Decline», en A. Portes, M. Castells y L.A. Benton (eds.), The Informal Economy: Studies in Advanced and Less Developed Countries, Baltimore y Londres, The John Hopkins University Press.

Stenning, A. (2005), "Out there and in here: Studying Eastern Europe in the West», Area 37, pp. 378-383.

Stepick, A. (1989), «Miami's Two Informal Sectors», en A. Portes, M. Castells y L.A. Benton (eds.), The Informal Economy: Studies in Advanced and Less Developed Countries, Baltimore y Londres, John Hopkins University Press. 
Termonen, M. (2004), «The relation of European labour and migration policies», Imatra, Finland, http://no-racism.net/article/900/ (2006-01-15).

Thérien, J.P. (2005), «Beyond the North-South Divide: The Two Tales of World Poverty», en R. Wilkinson (ed.), The Global Governance Reader, London, Routledge, Taylor \& Francis Group.

WADE, R.H. (2005), «Failing States and Cumulative Cauzation in the World System», Internaciónal Political Science Review 26, pp. 17-37.

WaLIGORSKI, C. (1990), The Political Theory of Conservative Economists, Lawrence, University Press of Kansas.

Wallace, C. y C. Haerpfer (2002), "Patterns of participación in the informal economy», en R. Neef y M. Stanculescu (eds.), The Social Impact of Informal Economies in Eastern Europe, Burlington, Ashgate.

Waterman, P. (2004), «Trade Unions, NGos and Global Social Justice: Another Tale to Tell», RISQ Reviews, http://www.risq.org/article383.html (14 de noviembre).

WCSDG (2004), «A Fair Globalización:Creating Opportunities for All», Ginebra, ILO.

Williamson, J. (1990), «What Washington Means by Policy Reform?», en J. Williamson (ed.), Latin American Adjustment: How Much Has Happened, Washington, DC, Institute for International Economic.

(2000), «What Should the World Bank Think about the Washington Consensus», The World Bank Research Observer 15, 251-264, http://wbro.oxfordjournals.org/cgi/reprint/15/2/251.pdf

Wolf, M. (2007), «Why America will need some elements of a welfare state», http://blogs. ft.com/wolfforum/2007/02/why_america_wil.html 
